Article

\title{
Manipulation of Culture Conditions: Tool for Correlating/Improving Lipid and Carotenoid Production by Rhodotorula glutinis
}

\author{
Nora Elfeky ${ }^{1,2} \mathbb{D}$, Mostafa Elmahmoudy ${ }^{1}$ and Yongming Bao ${ }^{1,3, *(\mathbb{D}}$ \\ 1 School of Bioengineering, Dalian University of Technology, Dalian 116024, China; \\ n0ra.mohamed1987@yahoo.com (N.E.); mostafa.elmahmoudy2018@gmail.com (M.E.) \\ 2 Faculty of Science, Botany Department, Menoufia University, Shebin El-koom 32511, Egypt \\ 3 School of Food and Environment Science and Engineering, Dalian University of Technology, \\ Panjin 124221, China \\ * $\quad$ Correspondence: biosci@dlut.edu.cn; Tel.: +86-133-3228-0036; Fax: +86-411-8470-6365
}

Received: 23 December 2019; Accepted: 16 January 2020; Published: 21 January 2020

\begin{abstract}
The coproduction of lipid and carotenoid by red yeasts in one cycle is more convenient and economical for the industrial sectors, while the kinetics correlation between both products under different culture conditions has been scarcely studied. This study is aiming to correlate the impact of different carbon sources, carbon to phosphorus ratio $(\mathrm{C} / \mathrm{P})$, temperature, aeration, $\mathrm{pH}$, and metals on dry cell weight, lipid (GC and fluorescence microscope), and carotenoid (HPLC) production by Rhodotorula glutinis, and applying a novel feeding approach using a $5 \mathrm{~L}$ bioreactor to enhance carotenoid and unsaturated fatty acid production by R. glutinis. Whatever the culture condition is, the reversible correlation between lipid and carotenoid production was detected. Remarkably, when adding $0.1 \mathrm{mM} \mathrm{BaCl}_{2}$, cellular lipid was significantly increased $14 \%$ more than the control, with $79.3 \%$ unsaturated fatty acid ( $46 \% \mathrm{C} 18: 2$ and C18:3) and 50\% $\gamma$-carotene, while adding $1 \mathrm{mM} \mathrm{NiSO}_{4}$, cellular carotenoid was enhanced around 53\% than the control (torulene $88 \%$ ) with $81 \%$ unsaturated fatty acid ( $61 \%$ oleic acid). Excitingly, $68.8 \mathrm{~g} / \mathrm{l}$ biomass with $41 \%$ cellular lipid (79\% unsaturated fatty acid) and $426 \mu \mathrm{g}_{\text {pigment }} / \mathrm{g}_{\mathrm{dcw}}$ cellular carotenoid $(29.3 \mathrm{mg} / \mathrm{L})(71 \%$ torulene) were obtained, when the $\mathrm{pH}$-temperature dual controlled process combined with metallo-sulfo-phospho-glucose feeding approach in the $5 \mathrm{~L}$ bioreactor during the accumulation phase was conducted. This is the first study on the kinetic correlation between lipid and carotenoid under different $\mathrm{C} / \mathrm{P}$ ratio and the dual effect of different metals like $\mathrm{NiSO}_{4}$ on lipid and carotenoid production by red oleaginous yeasts, which in turn significant for enhancing the coproduction of lipid and carotenoid by R. glutinis.
\end{abstract}

Keywords: Rhodotorula glutinis; lipid; carotenoid; metal; $\mathrm{NiSO}_{4}$; nile-red fluorescence dye; unsaturated fatty acid

\section{Introduction}

Red oleaginous yeasts are a broad group of yeasts, which are characterized by producing many valuable metabolites such as lipids and carotenoid [1], one of the main representative genus of those colored yeasts is Rhodotorula glutinis. R. glutinis can accumulate lipid up to $60 \%$ of its dry cell [2]. This yeast primarily synthesizes palmitic acid (C16:0), oleic acid (C18:1), linoleic acid (C18:2), and $\alpha$-linolenic acid (C18:3) [1].

Based on a nutritional classification, fatty acids that are not synthesized by humans and are indispensable for development and health are known as essential, while those produced by humans are classified as non-essential fatty acids [3]. In this context, linoleic and alpha-linolenic acids are 
polyunsaturated fatty acids (PUFA) classified as essential, while monounsaturated fatty acids (MUFA) like oleic acid are classified as a non-essential fatty acid that has been recently described as a regulator of immune function and health [4]. Although oleic acid is a non-essential fatty acid, it has many human health advantages. Oleic acid represents $70 \%-80 \%$ of olive oil composition, besides minor phenolic compounds [5]. In the last few years, many studies have described the contribution of olive oil to general health, partly due to its high oleic acid content [6,7], which was demonstrated to lead to a reduction in cholesterol levels, atherogenesis risk $[5,8,9]$, blood pressure, and daily antihypertensive drug intake [9]. In addition, oleic acid was demonstrated to induce beneficial anti-inflammatory effects on autoimmune diseases [10], protective effects on breast cancer, and improvement of immune system function [11,12].

Under certain conditions, R. glutinis can accumulate oleic acid in a ratio similar to olive oil [13], besides the variable accumulated amount from polyunsaturated fatty acid, i.e., linoleic and linolenic acid depending on either culture conditions or yeast strains [14]. Accordingly, this study aimed to investigate the possibilities to enhance and or improve the lipid profile of $R$. glutinis through the manipulation of culture conditions.

In addition to lipid production, $R$. glutinis can also produce carotenoids with variable quantities, mainly dependent on the yeast strains and culture conditions. Carotenoid are natural pigments, which received increased interest during the few last years due to the growing general concern for using organic pigment in the industrial and pharmaceutical sectors instead of synthetic ones. Four different individual carotenoids produced by $R$. glutinis, $\beta$-carotene, $\gamma$-carotene, torulene, and torularhodin were detected in the previous report [15].

Carotenoid is the primary source of vitamin A in the human diet, and they have health-promoting properties. Carotenoids reinforce the immune system of the body, accelerates the healing of wounds [16], and counteracts eye conditions, such as cataracts [17] or age-related macular degeneration [18]. Carotenoid supplements are commonly used as agents protecting the skin against harmful ultraviolet radiation $[19,20]$. Carotenoids may also be used in cancer prevention owing to their anti-oxidative properties [20]. Among carotenoid, $\beta$-carotene and $\gamma$-carotene have already been transferred industrial production, while torulene and torularhodin are still in the development stage, and more studies still need to be conducted to clarify their production conditions and maximize the yield to be suitable for upgrading to an industrial scale.

The biotechnological synthesis of both lipid and carotenoid is influenced by many factors involved in the processes that can affect yields and operation costs [14,21]. The type of species and growth conditions, i.e., temperature, $\mathrm{pH}$, type of substrate, variation in carbon to phosphorous $(\mathrm{C} / \mathrm{P})$ ratio, and oxygen not only influence the efficiency of either lipid or carotenoid accumulation but also their profile inside the yeast cell $[14,21]$.

The kinetics correlation studies between lipid and carotenoid production by red oleaginous yeasts under different carbon to nitrogen $(\mathrm{C} / \mathrm{N})$ molar ratios showed confusing results, as some authors reported a positive correlation between high $\mathrm{C} / \mathrm{N}$ and lipid and carotenoid production with a parallel increase of both lipid and carotenoid kinetics till the end of incubation time [22], while another study reported a negative correlation between lipid and carotenoid production under high $\mathrm{C} / \mathrm{N}$ ratio, as the highest carotenoid accumulation was observed under low $\mathrm{C} / \mathrm{N}$ ratio [23]. While our recent lab work showed that both lipid and carotenoid production was enhanced under high $\mathrm{C} / \mathrm{N}$ during the growth phase, then the negative correlation was detected to favor lipid accumulation during the accumulation phase [24]. The same study detected the effect of different carbon to sulfur (C/S) ratios on the kinetics of lipid and carotenoid production by R. glutinis, and cellular carotenoid was enhanced over cellular lipid under high $\mathrm{C} / \mathrm{N}$ ratio with decreasing $\mathrm{C} / \mathrm{S}$ ratio [24]. On the other hand, the effect of different $\mathrm{C} / \mathrm{P}$ molar ratio on carotenoid biosynthesis, thus as well the correlation between lipid and carotenoid production by red oleaginous yeasts under different $\mathrm{C} / \mathrm{P}$ ratios, were never studied before, although the role of phosphorus deficiency for enhancing lipid accumulation by oleaginous yeasts has been confirmed [25]. 
Metals, even at very low concentrations, pose threats to human and environmental health for their hazardous effects, persistence, and accumulation. Metals, such as copper, zinc, manganese, nickel, and iron, despite being toxic at a high concentration, they are essential for the growth of microorganisms in trace amounts acting as micronutrients contributing to the yeast's growth [26]. Only very few studies have been thus far focused on the effect of metals on either lipid or carotenoid production by the colored oleaginous microorganism, especially yeasts [27-30]. Meanwhile, no attempts have been made to evaluate the dual effects of the heavy metals on the simultaneous production of lipid and carotenoid by red oleaginous yeast. Our previous work stated the effect of the combined cultivation mode of low carbon to sulfur ratio $(C / S)$ with high carbon to nitrogen molar ratio $(C / N)$ in the presence of $0.7 \mathrm{mM}$ of aluminum sulfate for enhancing carotenoid production, specifically torulene by R. glutinis [24].

During the last 20 years, only a few studies have been conducted on the simultaneous production of lipid and carotenoid by red oleaginous yeasts [2,13,22-24]. Most authors stated the suitability of the produced lipid for biodiesel production, except for a recent study carried by Kot et al. [10], which stated the similarity of the produced lipid with olive oil composition. The carotenoid profile of $R$. glutinis reported by the most previously reported studies showed the dominance of $\beta$-carotene, while few authors $[23,24]$ reported the dominance of torularhodin and torulene. However, to make the coproduction of lipid and carotenoid from the red oleaginous yeasts a more economical process, the accumulated lipid should be more lavish with monounsaturated fatty acid (USFA) like oleic acid and polyunsaturated fatty acid (PUFA) instead of saturated fatty acid. As a result, a highly valuable colored fat can be produced at the end of the process, which can be further processed in the human health-related industries and food industry.

Continuously, this study aims to correlate between lipid and carotenoid production by R. glutinis and investigate the possibilities of improving the yield and profile of both lipid and carotenoid produced by R. glutinis through manipulation of culture conditions. Also, detect the dual role of some metals as a stress factor on lipid and carotenoid production. Followed by applying a novel fed-batch approach, which depends on the combined dual controlled of different physical and chemical conditions, as an attempt to improve the fatty acid and carotenoid profile produced by R. glutinis for the potential purpose of human consumption.

\section{Materials and Methods}

\subsection{The Yeast Strain and Media Compositions}

The oleaginous red yeast Rhodotorula glutinis (AS 2.703), which was obtained from the China General Microbiological Culture Collection Center (CGMCC) (Beijing, China), was used in this study. The yeast strain was cultivated on yeast extract peptone dextrose (YPD) agar slants (glucose $20 \mathrm{~g} / \mathrm{L}$, yeast extract $10 \mathrm{~g} / \mathrm{L}$, peptone $10 \mathrm{~g} / \mathrm{L}$, agar $15 \mathrm{~g} / \mathrm{L}$ ), then incubated at $28^{\circ} \mathrm{C}$ for 3 days and then preserved at $4{ }^{\circ} \mathrm{C}$ for further experiments.

Three different media were prepared, the seed culture media and the YPD broth media. Fermentation medium A (FMA), which contained (per liter) glucose (60 g), $\left(\mathrm{NH}_{4}\right)_{2} \mathrm{SO}_{4}(0.5 \mathrm{~g})$, yeast extract $(0.75 \mathrm{~g}), \mathrm{KH}_{2} \mathrm{PO}_{4}(1.5 \mathrm{~g})$, and $\mathrm{MgSO}_{4} .7 \mathrm{H}_{2} \mathrm{O}(1 \mathrm{~g})$, FMA was used to detect the effect of different culture conditions on $R$. glutinis growth, lipid, and carotenoid production (consider this basal condition as control C1). Fermentation medium $\mathrm{B}(\mathrm{FMB})$, which contained (per liter) glucose (60 g), $\left(\mathrm{NH}_{4}\right)_{2} \mathrm{SO}_{4}(0.9 \mathrm{~g}), \mathrm{KH}_{2} \mathrm{PO}_{4}(1.5 \mathrm{~g})$, and $\mathrm{MgSO}_{4} .7 \mathrm{H}_{2} \mathrm{O}(1.2 \mathrm{~g})$. This medium was used to detect the effect of different heavy metal stress on $R$. glutinis growth, lipid, and carotenoid production. FMB media was used as an optimized medium after optimizing the $\mathrm{C} / \mathrm{N}$ ratio, nitrogen source, and $\mathrm{C} / \mathrm{S}$ ratio for enhancing carotenoid production under a high $\mathrm{C} / \mathrm{N}$ ratio (consider this basal condition as control C2) [24]. The $\mathrm{pH}$ of the 3 culture media was adjusted at $\mathrm{pH}$, then $100 \mathrm{~mL}$ was distributed in $250 \mathrm{~mL}$ flasks followed by sterilization at $121^{\circ} \mathrm{C}$ for $20 \mathrm{~min}$ after inoculation with yeast cells, then the flasks were incubated at $28^{\circ} \mathrm{C}$ and $180 \mathrm{rpm}$. Otherwise, the different conditions were stated. Seed 
culture preparation and inoculation in the fermentation medium was fully explained in our previous work [24].

\subsection{Effect of Different Culture Conditions and Metals Stress on Growth, Lipid, and Carotenoid Production by} R. glutinis

Herein, sterilized FMA was prepared, replacing the carbon source (glucose C1) (Glu) with its equivalent amount of maltose (Mal), sucrose (Suc), lactose, starch, and glucose:sucrose (1:1) (Glu: Suc) to fix the initial $\mathrm{C} / \mathrm{N}$ molar ratio at 146 with all treatments and to study the effect of different carbon source on growth, lipid, and carotenoid production by $R$. glutinis.

To study the effect of different $\mathrm{pH}$ degree on growth, lipid, and carotenoid production by R. glutinis, the sterilized FMA was prepared while adjusting $\mathrm{pH}$ at different degrees; 3, 4, $5(\mathrm{C} 1), 6,7$, and 8 using $6 \mathrm{~N} \mathrm{HCl}$ for decreasing $\mathrm{pH}$ and $6 \mathrm{~N} \mathrm{NaOH}$ for increasing $\mathrm{pH}$.

To study the effect of different temperature degrees on growth, lipid, and carotenoid production by $R$. glutinis, after inoculating the sterilized FMA with the seed culture; the flasks were incubated at different temperature degrees of $25^{\circ} \mathrm{C}, 28^{\circ} \mathrm{C}(\mathrm{C} 1), 30^{\circ} \mathrm{C}$, and $32{ }^{\circ} \mathrm{C}$ under the same agitation condition.

To study the effect of different agitation speeds on growth, lipid, and carotenoid production by R. glutinis, after inoculating the sterilized FMA by the seed culture; the flasks were incubated at different agitation speeds of 150, 180 (C1), 200, and $220 \mathrm{rpm}$.

Continuously, the effect of different C/P molar ratios on growth, lipid, and carotenoid production by $R$. glutinis was studied. The sterilized FMA was prepared with different phosphorus concentration $0.5 \mathrm{~g} / \mathrm{L}, 1.5 \mathrm{~g} / \mathrm{L}(\mathrm{C} 1), 3 \mathrm{~g} / \mathrm{L}$, and $4.5 \mathrm{~g} / \mathrm{L}$ and fixed glucose concentration $(60 \mathrm{~g} / \mathrm{L})$ to prepare different initial C/P molar ratio 527, 176, 88, and 59, respectively.

Finally, the effect of different metal types and concentrations on growth, lipid, and carotenoid production by R. glutinis were studied as follows; a new fermentation medium FMB was prepared. After sterilization, different metals $\mathrm{ZnCl}_{2}, \mathrm{MnCl}_{2}, \mathrm{BaCl}_{2}, \mathrm{FeCl}_{3}, \mathrm{Fe}_{2}\left(\mathrm{SO}_{4}\right)_{3}, \mathrm{CuCl}_{3}, \mathrm{Cu}_{2}\left(\mathrm{SO}_{4}\right)_{3}, \mathrm{NiSO}_{4}$, and $\mathrm{LiCl}$ were added separately to the culture medium to prepare two initial concentrations of $0.1 \mathrm{mM}$ and $1 \mathrm{mM}$ from each metal. Afterward, the steps proceeded normally.

\subsection{Fed-Batch Cultivation of R. glutinis under Optimized Condition}

For fed-batch cultivation of $R$. glutinis, a 5 L bioreactor (biotech-5BG-700A, China, www.bxbio.com) was used using with the following medium: Glucose $30 \mathrm{~g} / \mathrm{L}$, sucrose $15 \mathrm{~g} / \mathrm{L}$; yeast extracts $15 \mathrm{~g} / \mathrm{L}$, peptone $8 \mathrm{~g} / \mathrm{L}$, ammonium sulfate $10 \mathrm{~g} / \mathrm{L}, \mathrm{MgSO}_{4} 3 \mathrm{~g} / \mathrm{L}, \mathrm{KH}_{2} \mathrm{PO}_{4} 3 \mathrm{~g} / \mathrm{L}$. To reduce the lag phase, the seed culture was prepared from the same medium, $150 \mathrm{~mL}$ in $500 \mathrm{~mL}$ flasks, after sterilization, 3 discs from $24 \mathrm{~h} \mathrm{R}$. glutinis plate were added to each flask then incubated at $30^{\circ} \mathrm{C}$ and $180 \mathrm{rpm}$ for $36 \mathrm{~h}$ (Mid exponential phase). The seed culture was added to the bioreactor vessel to start the experiment with $2.5 \mathrm{~L}$ as an initial volume. The dissolving oxygen (DO) was fixed above $40 \%$, pH was adjusted automatically. Herein, we conducted 2 separate experiments; the first one was the control at which a fixed temperature of $30^{\circ} \mathrm{C}, \mathrm{pH} 6$, and agitation speed $400 \mathrm{rpm}$ was used during the whole experiment. Glucose solution (100 g/ $100 \mathrm{~mL}$ distilled water) was continuously fed at the rate of $4.5 \mathrm{~g} / \mathrm{h}$ before the exhaustion of carbon source during the growth phase then to $5.5 \mathrm{~g} / \mathrm{h}$ during the accumulation phase till $128 \mathrm{~h}$. The residual glucose in the growth media was kept below $25 \mathrm{~g} / \mathrm{L}$.

On the other hand, a second experiment was carried out that was similar to the first one until $20 \mathrm{~h}$ (end of the growth phase), after that $\mathrm{Al}_{2} \mathrm{SO}_{4}, \mathrm{NiSO}_{4}, \mathrm{MnCl}_{2}, \mathrm{LiCl}$, and $\mathrm{BaCl}_{2}$ solutions were added separately to the bioreactor to prepare the following concentrations of $0.7 \mathrm{mM}, 0.5 \mathrm{mM}, 0.01 \mathrm{mM}$, $0.01 \mathrm{mM}$, and $0.01 \mathrm{mM}$, respectively. In addition, the temperature and $\mathrm{pH}$ were changed to $23^{\circ} \mathrm{C}$ and 4, respectively. The feeding solution consisted of glucose: $\mathrm{MgSO}_{4}: \mathrm{KH}_{2} \mathrm{PO}_{4}$ with a ratio of 100:0.2:0.2 (g/ $100 \mathrm{~mL}$ distilled water) was used to feed during the accumulation phase. The feeding rate was $5 \mathrm{~g} / \mathrm{h}$ till $128 \mathrm{~h}$ to keep the residual glucose below $25 \mathrm{~g} / \mathrm{L}$ in the medium. The samples were withdrawn every $12 \mathrm{~h}$ to detect dry cell weight (DCW), lipid, and carotenoid production by R. glutinis. 


\subsection{Detection of Dry Cell Weight (DCW) and Reducing Sugar in the Culture Media}

From the withdrawn samples, $5 \mathrm{~mL}$ were centrifuged at 10,000 rpm for $10 \mathrm{~min}$; the cells were washed twice with the same volume of sterilized distilled water, then freeze-dried (lyophilized) and weighted for the determination of dry cell weight (DCW) [31]. The supernatant was used for measuring residual sugar using the 3, 5-dinitrosalicylic acid method [32]. For non-reducing sugars like sucrose, firstly, the acid was hydrolyzed, followed by incubating at $90^{\circ} \mathrm{C}$ in a hot water bath for $15 \mathrm{~min}$ and then neutralized to $\mathrm{pH} 7$ by $\mathrm{NaOH} 6 \mathrm{~N}$. Then, the reducing sugar detected by the DNS method [33].

\subsection{Fluorescence Microscopic Examination of Nile-Red Treated Cells}

After the incubation period, the cells collected from $100 \mu \mathrm{L}$ were washed twice and suspended in $10 \mathrm{mM}$ phosphate buffer with $0.15 \mathrm{M}$ potassium hydroxide, $\mathrm{pH} 7$, then mixed with $10 \mu \mathrm{L}$ of Nile red solution ( $1 \mathrm{mg}$ of Nile-red in $1 \mathrm{~mL}$ of acetone and kept in the dark at $\left.4{ }^{\circ} \mathrm{C}\right)$. After $5 \mathrm{~min}$ in the dark, the cells were viewed using an Olympus IX71 fluorescence microscope equipped with a blue fluorescence cube and IX71 frame camera port (Tokyo, Japan) to visualize the cell shape and golden fluorescent lipid bodies inside the cell [34]. The corrected total cell fluorescence (CTCF) for each treatment was calculated using image $\mathrm{j}$ software by using the following equation [35]:

$$
\text { CTCF }=\text { Integrated density }-(\text { Mean Area of selected Cells } \times \text { Mean flourescence of background readings })
$$

The area of 5 random cells was chosen from each figure, and their mean was used for the calculations.

\subsection{Total Lipid Detection and GC Analysis of Fatty Acid Methyl Ester}

The total lipids in the yeast cells were detected using the sulfo-phospho vanillin method [36], as briefly described at Elfeky et al. [24]. For determining the fatty acid composition, transesterification of the samples was carried out according to Van Wychen et al. [37]. The freeze-dried cells $(10 \mathrm{~mL}$ yeast suspension) were added to vials previously heated at $85^{\circ} \mathrm{C}$, then $200 \mu \mathrm{l}$ of chloroform: methanol $(2: 1 v / v)$ with $300 \mu \mathrm{l}$ of $0.6 \mathrm{M} \mathrm{HCl}$ : Methanol was added. All vials were sealed with caps and vortexed well to mix the contents and then heated again at $85{ }^{\circ} \mathrm{C}$ for $60 \mathrm{~min}$. After heating, the vials were removed and allowed to cool for $15 \mathrm{~min}$ at room temperature. One milliliter of hexane was added and vortexed well to mix the content, then $1 \mathrm{ml}$ of $0.1 \% \mathrm{NaOH}$ solution was added to wash the acid. This was centrifuged at $2000 \mathrm{rpm}$ for $5 \mathrm{~min}$ to allow phase separation. The hexane layer was transferred to a new GC vial for GC analysis. The fatty acid methyl ester was analyzed by using an Agilent 7890A GC equipped with an autosampler and FID. The capillary column HP-FFAP ( $25 \mathrm{~m}$ length, $0.2 \mathrm{~mm}$ ID, $0.33 \mu \mathrm{m}$ film thickness) was used for analytical separation. The temperatures of the injector and detector were set at $240{ }^{\circ} \mathrm{C}$. The column temperature was kept at $180^{\circ} \mathrm{C}$ for $2 \mathrm{~min}$ and then raised to $240{ }^{\circ} \mathrm{C}$ for $2 \mathrm{~min}$ at a rate of $7^{\circ} \mathrm{C} / \mathrm{min}$. Fatty acid was identified by a comparison of their retention times with those of standard ones, quantified as a percent of the total of the FAMES content.

\subsection{Total Carotenoid Extraction, Quantifying, and Identification}

The extraction of carotenoid, quantifying, and identification was explained by Elfeky et al. [24] according to Frengova et al. [38] and Weber et al. [39].

\subsection{Kinetics Analysis of Fermentation}

According to Certik and Shimizu [40], the primary parameters determined in this study were to be: Dry cell weight (DCW) g/L, total lipid (TL) g/L, and total pigment (TP) $\mathrm{mg} / \mathrm{L}$. The relative productivity (RP) represents the cellular lipid (L-RP) and carotenoid $\left(\left(\mathrm{g}_{\mathrm{Lipid}} / \mathrm{g}_{\mathrm{DCW}} \times 100\right) \%\right.$ and $\mathrm{mg}_{\text {pigment }} / 100 \mathrm{~g}_{\mathrm{DCW}}$, respectively). The yield of product $(Y)$ represents the entire amount of DCW (DCW-Y), TL (TL-Y), and TP (TP-Y) formation from the total consumed substrate $\mathrm{g}_{\mathrm{DCW}} / 100 \mathrm{~g}_{\text {glucose }}, \mathrm{g}_{\text {lipid }} / 100 \mathrm{~g}_{\text {glucose}}$, and 
$\mathrm{mg}_{\text {pigment }} / 100 \mathrm{~g}_{\text {glucose }}$, respectively. The rate of product synthesis (P-SR) was the average speed of total production of TL (L-SR) $\mathrm{g} / \mathrm{L} \cdot$ day and TP $(\mathrm{Car}-\mathrm{SR}) \mu \mathrm{g} / \mathrm{L} \cdot$ day and calculated using the following equation:

$$
\begin{gathered}
L-S R(\text { Lipid synthesis rate })=\frac{d T L}{d t}=\frac{T L_{2}-T L_{1}}{t_{2}-t_{1}} \\
\text { Car-SR (Carotenoid synthesis rate) }=\frac{d T P}{d t}=\frac{T p_{2}-T p_{1}}{t_{2}-t_{1}}
\end{gathered}
$$

where $T L_{1}$ and $T L_{2}$ are the lipid concentrations $(\mathrm{g} / \mathrm{L})$ at times $t 1$ and $t 2$, respectively, and $T P_{1}$ and $T P_{2}$ are the carotenoid concentrations $(\mu \mathrm{g} / \mathrm{L})$ at time $t_{1}$ and $t_{2}$, respectively [24].

\subsection{Statistical Analysis}

All experiments were repeated 3 times. The data were expressed as the mean $\pm \mathrm{SD}$. Statistical analysis was carried out using Origin 8.6 (Northampton, MA USA), and comparisons of each group were evaluated using one-way analysis of variance (ANOVA), multivariate, and correlation coefficient using SPSS 19 software (IBM, Chicago, IL, USA). The results were considered statistically significant at $p<0.05$.

\section{Results and Discussion}

\subsection{Effect of Different Culture Conditions on Growth, Lipid, and Carotenoid Production by R. glutinis}

\subsubsection{Microscopic Examination of R. glutinis Cellular Shapes and Lipid Bodies}

The effect of different carbon sources on the lipid bodies accumulated inside the Nile red-stained yeast cells and examined under fluorescence microscopy using blue fluorescence mode is shown in Figure 1. The highly accumulated lipid bodies depend on the CTCF values that were observed with the combination of glucose and sucrose as a carbon source (Figure $1 \mathrm{~b}$ and Figure S1a) followed by glucose as a carbon source (Figure $1 \mathrm{a}$ and Figure S1a). While using sucrose as a sole carbon source, there was a considerable reduction in the lipid bodies (Figure 1c). In contrast to sucrose, the lipid bodies were scarcely observed when maltose was used as a carbon source, which showed the lowest CTCF value (Figure 1d and Figure S1a). Studying the lipid bodies accumulation after growing R. glutinis under different initial $\mathrm{pH}$ levels is represented in Figure 2 and Figure S1b. As observed in Figure 2a-c, the acidic medium enhanced lipid accumulation and lipid droplets enlargement as well; the best accumulation condition with the highest CTCF value was provided at $\mathrm{pH} 4$. Increasing $\mathrm{pH}$ to 8 was led to a significant decrease in the lipid bodies with decreasing CTCF value in turn, Figure $2 \mathrm{~d}-\mathrm{f}$ and Figure S1b.

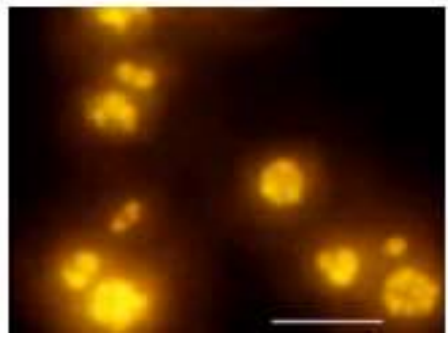

(a)

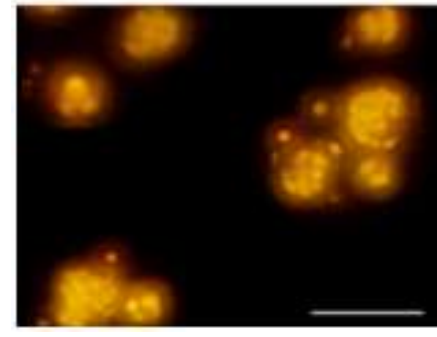

(b)

Figure 1. Cont. 


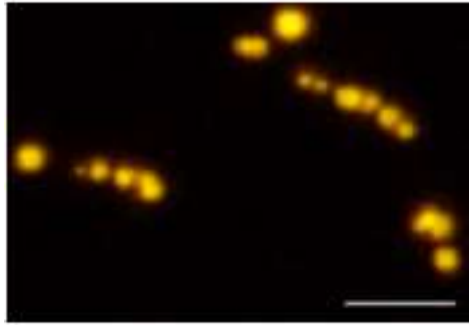

(c)

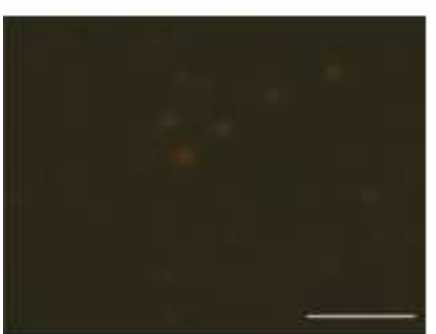

(d)

Figure 1. Fluorescence microscopy examination of Nile red-stained yeast cells after growing on lipid accumulating media supplemented with different carbon sources after the $6^{\text {th }}$ day: (a) Glucose; (b) glucose and sucrose (1:1); (c) sucrose; (d) maltose. The magnification bar is equal to $10 \mu \mathrm{m}$.

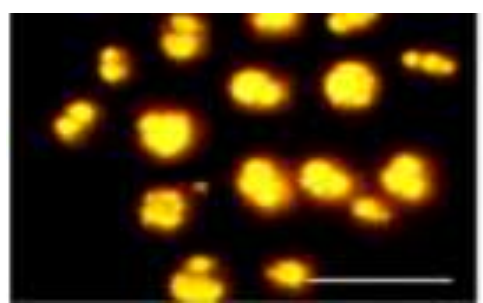

(a)

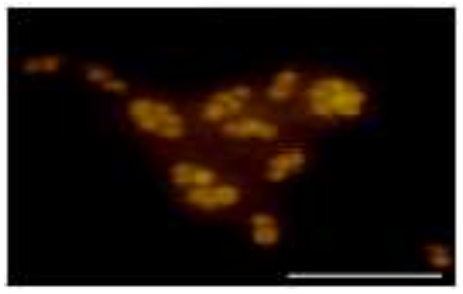

(d)

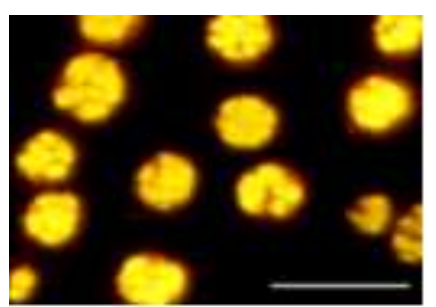

(b)

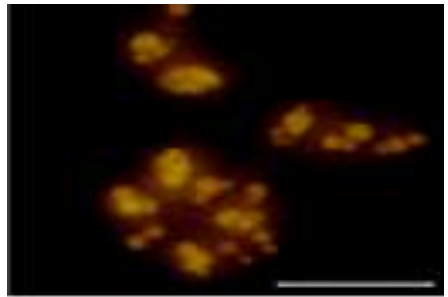

(e)

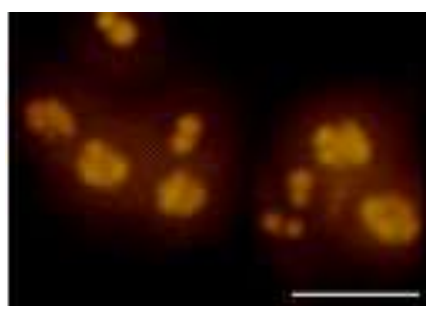

(c)

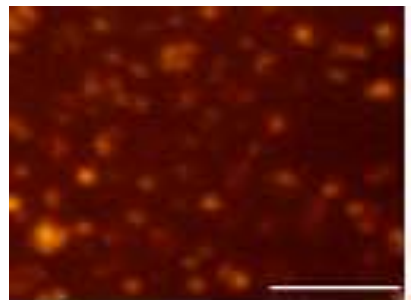

(f)

Figure 2. Fluorescence microscopy examination of Nile red-stained yeast cells after growing on lipid accumulating media with different $\mathrm{pH}$ for 6 days: (a) 3 ; (b) 4 ; (c) 5 ; (d) 6 ; (e) 7 ; (f) 8 . The magnification bar is equal to $10 \mu \mathrm{m}$.

The temperature could be an essential physical factor that significantly affects the lipid body accumulation. As represented in Figure 3, the lowest incubating temperature of $25{ }^{\circ} \mathrm{C}$ (Figure 3a) enhanced the lipid bodies accumulation compared to the highest temperature of $32{ }^{\circ} \mathrm{C}$ (Figure $3 \mathrm{~d}$ ), which showed the lowest CTCF value (Figure S1c). On the other hand, the highest CTCF value was detected at $30^{\circ} \mathrm{C}$, Figure $3 \mathrm{c}$ and Figure S1c.

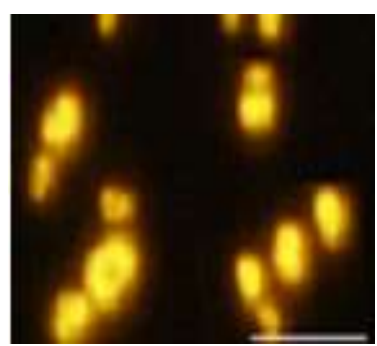

(a)

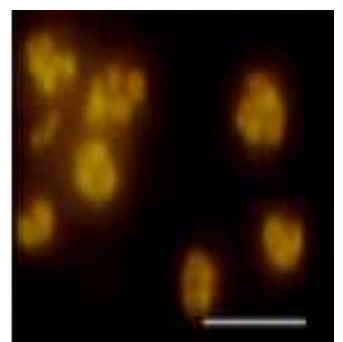

(b)

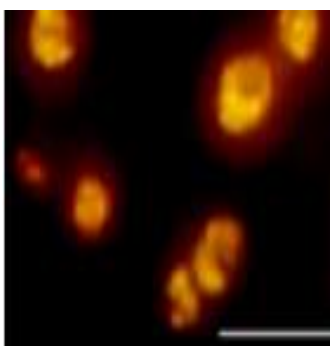

(c)

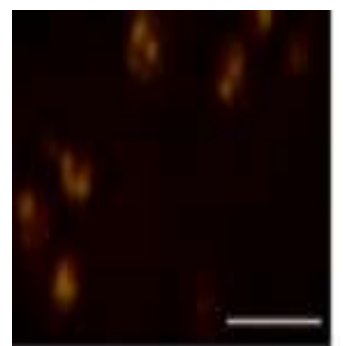

(d)

Figure 3. Fluorescence microscopy examination of Nile red-stained yeast cells after growing on lipid accumulating media at different temperatures degrees for 6 days: $(\mathbf{a}) 25^{\circ} \mathbf{C}$. (b) $28^{\circ} \mathbf{C}$. (c) $30^{\circ} \mathbf{C}$. (d) $32^{\circ} \mathbf{C}$. The magnification bar is equal to $10 \mu \mathrm{m}$. 
Continuously, the impact of different agitation speeds on the lipid bodies accumulation under a fluorescence microscope is represented in Figure 4. Firstly, the low agitation speed of $150 \mathrm{rpm}$ showed a few lipid bodies with the lowest CTCF compared to other groups, Figure 4a, Figure S1d, and the highest CTCF value was detected with $200 \mathrm{rpm}$ treatment, Figure 4c and Figure S1d.

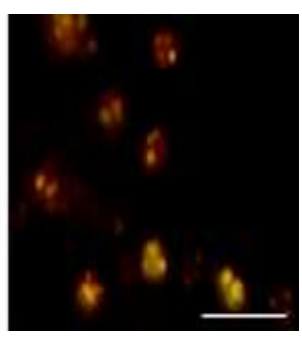

(a)

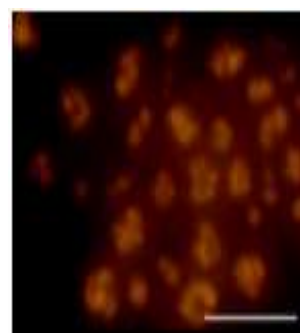

(b)

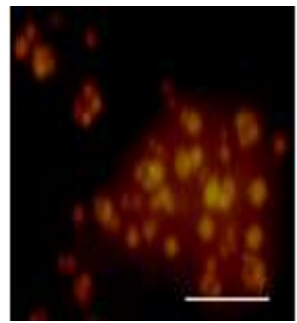

(c)

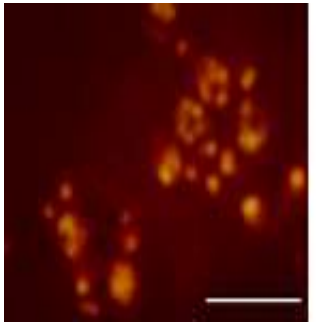

(d)

Figure 4. Fluorescence microscopy examination of Nile red-stained yeast cells after growing on lipid accumulating media under different agitation speed for 6 days: (a) $150 \mathrm{rpm}$. (b) $180 \mathrm{rpm}$. (c) $200 \mathrm{rpm}$. (d) $220 \mathrm{rpm}$. The magnification bar is equal to $10 \mu \mathrm{m}$.

The earlier studies stated the enhancement role of phosphorus deficiency on lipid accumulation and lipid droplets formation [25]. The microscopic examination of the Nile-red fluorescence yeast cells after growing on different $\mathrm{C} / \mathrm{P}$ ratio media showed a great decrease in lipid bodies number and size, thus as well the CTCF value as the phosphorus concentration gradually increased from $0.5 \mathrm{~g} / \mathrm{L}$ (Figure $5 \mathrm{a}$ and Figure S1e) to $1.5 \mathrm{~g} / \mathrm{L}$ (Figure $5 \mathrm{~b}$ ) then $3 \mathrm{~g} / \mathrm{L}$ (Figure $5 \mathrm{c}$ ) and finally $4.5 \mathrm{~g} / \mathrm{L}$ (Figure $5 \mathrm{~d}$ ).

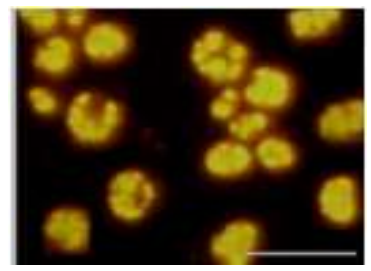

(a)

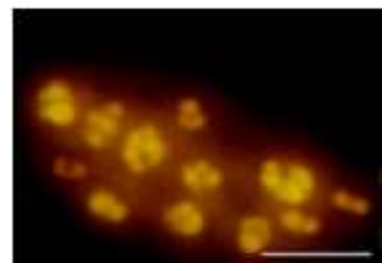

(b)

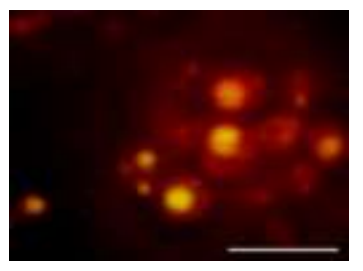

(c)

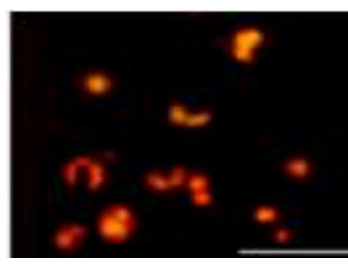

(d)

Figure 5. Fluorescence microscope examination of Nile red-stained yeast cells after growing on lipid accumulating media with different starter phosphorus concentrations for 6 days; (a) $0.5 \mathrm{~g} / \mathrm{L},(\mathbf{b}) 1.5 \mathrm{~g} / \mathrm{L}$, (c) $3 \mathrm{~g} / \mathrm{L}$, (d) $4.5 \mathrm{~g} / \mathrm{L}$. The magnification bar is equal to $10 \mu \mathrm{m}$.

3.1.2. The Growth, Lipid, and Carotenoid Production by R. glutinis under Different Culture Conditions

The effect of manipulating different culture conditions on the growth, lipid, and carotenoid production by R. glutinis is represented in Table 1 . 
Table 1. The effect of manipulating culture conditions on R. glutinis growth, lipid, and carotenoid production.

\begin{tabular}{|c|c|c|c|c|c|c|c|c|c|c|}
\hline \multirow{3}{*}{ Factor } & & \multirow{3}{*}{$\mathrm{T}$ (Day) } & \multicolumn{2}{|l|}{ DCW } & \multicolumn{3}{|l|}{ Lipid } & \multicolumn{3}{|l|}{ Carotenoid } \\
\hline & & & \multirow{2}{*}{ DCW g/L } & \multirow{2}{*}{$\begin{array}{l}\text { DCW-Y } \\
\text { g/g glu }\end{array}$} & \multirow{2}{*}{$\mathrm{TL} g / \mathrm{L}$} & \multirow{2}{*}{ TL-Y \% } & \multirow{2}{*}{$\begin{array}{l}\text { TL-RP } \\
\text { g/gdcw }\end{array}$} & \multirow{2}{*}{ TP mg/L } & \multirow{2}{*}{$\begin{array}{l}\text { Car-Y } \\
\mathrm{mg} / \mathbf{1 0 0} \mathrm{g} \text { glu }\end{array}$} & \multirow{2}{*}{$\begin{array}{l}\text { Car-RP } \\
\mu \mathrm{g} / \mathrm{g} \mathrm{dcw}\end{array}$} \\
\hline & & & & & & & & & & \\
\hline \multirow{6}{*}{$\begin{array}{l}\text { Carbon } \\
\text { sources }\end{array}$} & $\mathrm{C} 1$ & $6^{\text {th }}$ & $10.5 \pm 0.10$ & 26.1 & $5.00 \pm 0.14$ & 18.0 & 47.7 & $0.81 \pm 0.09$ & 17.3 & 77.8 \\
\hline & \multirow{2}{*}{ Suc } & $3^{\text {rd }}$ & $5.60 \pm 0.04$ & 34.4 & $1.80 \pm 0.05$ & 11.0 & 31.9 & $0.45 \pm 0.08$ & 27.3 & 79.4 \\
\hline & & $6^{\text {th }}$ & $8.70 \pm 0.08$ & 24.0 & $4.00 \pm 0.10$ & 16.9 & 45.5 & $0.70 \pm 0.03$ & 19.9 & 80.6 \\
\hline & Glu + Suc & $6^{\text {th }}$ & $10.7 \pm 0.50$ & 21.1 & $5.30 \pm 0.20$ & 16.0 & 49.4 & $0.96 \pm 0.07$ & 17.9 & 89.9 \\
\hline & \multirow{2}{*}{ Mal } & $3^{\text {rd }}$ & $6.00 \pm 0.09$ & 36.6 & $0.64 \pm 0.20$ & 3.90 & 10.6 & $0.33 \pm 0.06$ & 20.4 & 55.7 \\
\hline & & $6^{\text {th }}$ & $9.30 \pm 0.10$ & 35.0 & $2.70 \pm 0.50$ & 22.5 & 29.5 & $0.54 \pm 0.11$ & 21.8 & 58.0 \\
\hline \multirow{9}{*}{$\mathrm{pH}$} & \multirow{2}{*}{3} & $3^{\text {rd }}$ & $6.50 \pm 1.70$ & 33.0 & $2.80 \pm 0.02$ & 14.2 & 42.9 & $0.39 \pm 0.06$ & 19.7 & 59.5 \\
\hline & & $6^{\text {th }}$ & $9.90 \pm 2.20$ & 35.7 & $4.90 \pm 0.55$ & 22.1 & 49.3 & $0.46 \pm 0.15$ & 7.80 & 46.8 \\
\hline & $\mathrm{C} 1$ & $6^{\text {th }}$ & $10.5 \pm 0.10$ & 26.1 & $5.00 \pm 0.14$ & 18.0 & 47.7 & $0.81 \pm 0.09$ & 17.3 & 77.8 \\
\hline & 6 & $3^{\text {rd }}$ & $6.60 \pm 0.53$ & 47.6 & $1.97 \pm 0.06$ & 14.3 & 30.2 & $0.59 \pm 0.02$ & 42.9 & 90.1 \\
\hline & 6 & $6^{\text {th }}$ & $10.5 \pm 1.00$ & 27.6 & $4.74 \pm 0.46$ & 19.2 & 45.1 & $0.89 \pm 0.10$ & 21.1 & 85.0 \\
\hline & & $3^{\text {rd }}$ & $6.40 \pm 1.40$ & 46.7 & $1.86 \pm 0.37$ & 13.5 & 28.9 & $0.56 \pm 0.04$ & 40.8 & 87.5 \\
\hline & r & $6^{\text {th }}$ & $9.50 \pm 0.80$ & 26.8 & $4.04 \pm 0.36$ & 18.9 & 42.3 & $0.80 \pm 0.06$ & 20.7 & 84.2 \\
\hline & 8 & $3^{\text {rd }}$ & $6.10 \pm 1.10$ & 46.3 & $0.55 \pm 0.31$ & 4.20 & 9.00 & $0.48 \pm 0.02$ & 36.4 & 78.5 \\
\hline & 0 & $6^{\text {th }}$ & $9.00 \pm 1.10$ & 21.4 & $2.30 \pm 0.30$ & 12.6 & 25.3 & $0.73 \pm 0.01$ & 18.3 & 80.9 \\
\hline & 2 & $3^{\text {rd }}$ & $5.70 \pm 0.34$ & 47.6 & $1.36 \pm 0.11$ & 11.4 & 24.0 & $0.44 \pm 0.10$ & 36.7 & 77.1 \\
\hline & 20 & $6^{\text {th }}$ & $8.20 \pm 0.30$ & 24.7 & $3.63 \pm 0.33$ & 22.1 & 44.2 & $0.63 \pm 0.12$ & 19.0 & 77.0 \\
\hline & 150 & $3^{\text {rd }}$ & $6.30 \pm 0.27$ & 48.3 & $1.77 \pm 0.35$ & 13.6 & 28.1 & $0.47 \pm 0.10$ & 36.4 & 75.3 \\
\hline & 150 & $6^{\text {th }}$ & $9.50 \pm 0.48$ & 26.4 & $3.50 \pm 0.33$ & 14.6 & 37.2 & $0.68 \pm 0.10$ & 17.1 & 71.7 \\
\hline & 180 & $3^{\text {rd }}$ & $6.70 \pm 0.05$ & 47.5 & $2.40 \pm 0.20$ & 16.6 & 35.0 & $0.57 \pm 0.20$ & 39.8 & 83.8 \\
\hline Agitation & $\mathrm{C} 1$ & $6^{\text {th }}$ & $10.4 . \pm 0.1$ & 25.6 & $5.00 \pm 0.16$ & 18.2 & 47.8 & $0.81 \pm 0.10$ & 16.7 & 77.2 \\
\hline & 200 & $3^{\text {rd }}$ & $7.50 \pm 0.50$ & 47.2 & $2.60 \pm 0.12$ & 16.6 & 35.3 & $0.61 \pm 0.20$ & 38.5 & 81.6 \\
\hline & 200 & $6^{\text {th }}$ & $11.0 \pm 0.70$ & 24.9 & $5.40 \pm 0.30$ & 19.3 & 48.8 & $0.89 \pm 0.20$ & 19.9 & 81.0 \\
\hline & วา & $3^{\text {rd }}$ & $7.60 \pm 0.50$ & 43.9 & $2.60 \pm 0.32$ & 15.0 & 34.2 & $0.61 \pm 0.20$ & 35.4 & 80.6 \\
\hline & $2 \angle 0$ & $6^{\text {th }}$ & $11.0 \pm 0.80$ & 23.3 & $5.20 \pm 0.22$ & 17.7 & 47.1 & $0.89 \pm 0.03$ & 19.2 & 81.2 \\
\hline & 527 & $3^{\text {rd }}$ & $6.56 \pm 1.60$ & 41.5 & $2.61 \pm 0.04$ & 16.5 & 39.8 & $0.50 \pm 0.17$ & 31.6 & 76.0 \\
\hline & 527 & $6^{\text {th }}$ & $10.2 \pm 1.90$ & 21.6 & $5.30 \pm 0.08$ & 16.1 & 52.1 & $0.62 \pm 0.11$ & 7.33 & 60.9 \\
\hline & 176 & $3^{\mathrm{rd}}$ & $6.80 \pm 2.20$ & 47.5 & $2.36 \pm 0.20$ & 16.6 & 35.0 & $0.57 \pm 0.16$ & 39.8 & 83.8 \\
\hline $\mathrm{C} / \mathrm{P}$ & $\mathrm{C} 1$ & $6^{\text {th }}$ & $10.4 \pm 2.60$ & 25.3 & $5.10 \pm 0.16$ & 19.0 & 49.1 & $0.80 \pm 0.10$ & 16.6 & 77.4 \\
\hline & & $3^{\text {rd }}$ & $7.60 \pm 2.60$ & 51.2 & $1.60 \pm 0.04$ & 10.8 & 21.2 & $0.65 \pm 0.02$ & 43.5 & 85.0 \\
\hline & 88 & $6^{\text {th }}$ & $11.0 \pm 0.60$ & 25.9 & $3.50 \pm 0.04$ & 14.5 & 31.8 & $0.94 \pm 0.06$ & 22.3 & 85.4 \\
\hline & & $3^{\text {rd }}$ & $8.09 \pm 1.70$ & 53.7 & $0.64 \pm 0.05$ & 4.20 & 7.90 & $0.69 \pm 0.04$ & 45.8 & 85.3 \\
\hline & 59 & $6^{\text {th }}$ & $11.5 \pm 1.70$ & 26.7 & $2.30 \pm 0.06$ & 12.6 & 19.5 & $0.99 \pm 0.04$ & 23.3 & 85.9 \\
\hline
\end{tabular}

The data are the mean \pm SD of three separate biological samples. The significance of each condition is represented separately in the Supplementary Materials Tables S1-S5.

Firstly, the effect of different carbon sources on the growth, lipid, and carotenoid production showed a significant variation in the detected parameters between different carbon sources. The yeast strain was unable to grow on neither starch nor lactose (data are not shown), while a low growth rate was observed with maltose and sucrose when used as a sole carbon source, which was statistically significant with glucose after 3 days ( $p=0.008$, Table S1). Using a combined carbon source from glucose and sucrose did not significantly increase the growth compared with glucose but was significant with sucrose ( $p=0.01$, Table S1). On the same pattern, the growth efficiency (DCW-Y) was almost the same with glucose and Glu + Suc and was decreased with sucrose and maltose. 
On the other hand, a combination of glucose and sucrose efficiently improved the lipid and carotenoid production compared with the individual sources; glucose and sucrose. Around 5\% (not significant $p>0.05)$ and $26.5 \%(p=0.021)$ increase was observed for lipid production, respectively, while a $15 \%$ and $30 \%$ increase was detected for carotenoid production, respectively, after 6 days. Thus, the highest value of TL-RP, L-SR, Car-RP, and Car-SR was observed with the combination of glucose and sucrose as carbon sources recording around 49.4\% (after 6 days), $0.89 \mathrm{~g} / \mathrm{L}$.day (after 6 days), $92.3 \mu \mathrm{g} / \mathrm{g}$ (after 3 days), and $221.8 \mu \mathrm{g} / \mathrm{L}$.day (after 3 days), respectively, shown in Table 1 and Table S1. The multivariate analysis showed a significant difference between the dependent variable DCW after 3 and 6 days with glucose $(p=0.05)$ and Glu + Suc $(p=0.004)$, while TL was significant with all carbon sources after 3 and 6 days $(p<0.003)$, and carotenoid was only significant with carbon sources after 6 days $(p<0.003$, Table $\mathrm{S} 2)$.

The enhancement of the growth rate and lipid yield by Rhodosporidium kratochvilovae HIMPA1 was also detected when the mixture glucose + fructose + sucrose was used as a carbon source. The DCW and TL was $15.56 \mathrm{~g} / \mathrm{L}$ and $9.26 \mathrm{~g} / \mathrm{L}$, respectively, compared with $14.15 \mathrm{~g} / \mathrm{L}$ and $8.0 \mathrm{~g} / \mathrm{L}$, respectively, when glycerol was used as a sole carbon source [41], which supported our suggestion that points to the combination of different carbon sources at the culture media, which may enhance the growth and metabolite production by microorganisms.

Secondly, the studied yeast strain showed the ability to grow at a wide range of $\mathrm{pH}$ degrees from 3 to 8 , Table 1 and Table S3. The highest growth rate was observed at $\mathrm{pH} 5$ and 6 , as the growth was almost the same around 10.4 and $10.5 \mathrm{~g} / \mathrm{L}$, respectively. Thus, as well the growth yield, which was above $47 \%$, the growth decreased around $6 \%$ with $\mathrm{pH} 3(p=0.01)$ and $\mathrm{pH} 4(p=0.027)$, while recording around a $14 \%$ decrease with alkaline $\mathrm{pH} 8(p=0.001)$, shown in Table 1 and Table S3. This result indicates the ability of this yeast to grow well, even under a highly acidic environment. The same result was reported by Karamerou [42] when R. glutinis was able to grow well on glycerol at pH 2.6.

The statistical analysis of total lipid showed significant differences between all treatments with $\mathrm{pH} 8(p<0.01)$ after 3 and 6 days (Table S3). The TL for acidic $\mathrm{pH}$ was almost the same between 4.9 and $5.2 \mathrm{~g} / \mathrm{L}$, even the differences in the total biomass. Therefore, the Lower $\mathrm{pH}$ was observed to accelerate lipogenesis more than high $\mathrm{pH}$; the TL-RP was recorded around $42.9 \%$ and $40.4 \%$ after 3 days with $\mathrm{pH} 3$ and $\mathrm{pH} 4$, respectively, which represented around an $18 \%$ increase with $\mathrm{pH} 5$, and a $41 \%$ increase with alkaline $\mathrm{pH} 8$ (Table 1). In addition, the reduction in the total lipid with $\mathrm{pH} 3$ and $\mathrm{pH} 4$ may be related to the considerable reduction of $\mathrm{pH}$ after growing and producing acid, which subsequently led to a rapid $\mathrm{pH}$ decrease compared with the other higher $\mathrm{pH}$ levels, and the negative effect on the yeast metabolic activity. Similarly, the optimal medium $\mathrm{pH}$ to produce lipid by the red yeast Rhodosporidium toruloides NCYC 921 and Rhodotorula glutinis IIP-30 was 4.0 with glucose feeding in fed-batch fermentation [43] and [44], respectively. Another recent study recorded an optimum $\mathrm{pH}$ for lipid production at 5.5 when $R$. kratochvilovae was cultivated on a medium supplemented with glucose [45]. In contrast to lipids, the gradual increase in the total pigment production and Car-RP was observed with further increasing of $\mathrm{pH}$, recording the highest value at $\mathrm{pH} 6,0.894 \mathrm{mg} / \mathrm{L}$ at the $6^{\text {th }}$ day, and $90.1 \mu \mathrm{g} / \mathrm{g}_{\mathrm{dcw}}$ at the $3^{\text {rd }}$ day, respectively, which represented around a $30 \mu \mathrm{g} / \mathrm{g}_{\mathrm{dcw}}$ increase than $\mathrm{pH} 3$ and around $9 \mu \mathrm{g} / \mathrm{g}_{\mathrm{dcw}}$ than $\mathrm{pH} 8$ (Table 1). Other strains like Rhodosporidium toruloides NCYC 921 and Rhodotorula mucilaginosa showed the optimum $\mathrm{pH}$ at 5 and 6.6 when cultivated on glucose and salted cheese whey, respectively $[43,46]$.

The multivariate test showed a significant difference between the DCW after 6 days and TL with different $\mathrm{pH}$ treatments, while the significance of carotenoid was only detected with $\mathrm{pH} 3$ after 6 days (Table S4).

Thirdly, the temperature had a great effect on the yeast growth rate, lipid and carotenoids production. The highest growth rate was observed at $30^{\circ} \mathrm{C}$ after 6 days $10.9 \mathrm{~g} / \mathrm{L}$, which represents a significant increase around $24.7 \%(p=0.007)$, and $32 \%(p=0.000)$ than 25 and $32{ }^{\circ} \mathrm{C}$, respectively. While the highest DCW-Y was observed with a lower incubating temperature than higher temperature treatments, shown in Table 1 and Table S5. 
Lipid as a function of different temperatures treatments, the highest TL, TL-RP, and TL-SR was observed at $30{ }^{\circ} \mathrm{C}$, which was $5.3 \mathrm{~g} / \mathrm{L}( \pm 0.37), 49.1 \%$, and $0.98 \mathrm{~g} / \mathrm{L}$.day, respectively, at 6 days. And decreased significantly with 32 and $25^{\circ} \mathrm{C}$, around $27 \%( \pm 0.33, p=0.001)$ and $34 \%( \pm 0.35, p=0.001)$, respectively, compared with $28{ }^{\circ} \mathrm{C}$ treatment (Table 1 and Table S5). Other yeast strains showed different optimum temperatures for biomass and lipid production; the optimum temperature of Rhodotorula kratochvilovae was $30^{\circ} \mathrm{C}$, producing around $56 \%$ cellular lipid [45].

On the same pattern, the best temperature for carotenoid production was $28{ }^{\circ} \mathrm{C}, \mathrm{TP}$ was $0.81 \mathrm{mg} / \mathrm{L}$ $( \pm 0.09)$ on the $6^{\text {th }}$ day with cellular carotenoid around $84.2 \mu \mathrm{g} / \mathrm{g}_{\mathrm{dcw}}$ on the $3^{\text {rd }}$ day, this result was statistically significant with 25 and $32{ }^{\circ} \mathrm{C}$, which represented around an $8 \%(p=0.042)$, and $11 \%$ $(p=0.014)$ increase than TP at 25 and $32{ }^{\circ} \mathrm{C}$, respectively. Similarly, the optimum temperature for either biomass or carotenoid production by Rhodotorula sp. RY1801 was $28^{\circ} \mathrm{C}$ when glucose was used as a carbon source [47]. Another study investigating the effect of different temperature degrees on Sporobolomyces ruberrimus carotenoid using glycerol as a carbon source, the result revealed that the carotenoid production occurred whenever the temperature was kept between $19{ }^{\circ} \mathrm{C}$ and $27^{\circ} \mathrm{C}$, but at $31{ }^{\circ} \mathrm{C}$ the cells remained colorless, and no pigment production was seen [48]. The multivariate test showed a significance of the DCW and TL with different temperature treatments; $28^{\circ} \mathrm{C}(p=0.000)$ and $30{ }^{\circ} \mathrm{C}(p=0.000)$, while the significance of carotenoid was only detected with $28^{\circ} \mathrm{C}(p=0.014)$ and $30^{\circ} \mathrm{C}(p=0.01)$ after 6 days (Table S6).

It has been suggested that oleaginous yeasts require substantial oxygen supply for energy and biosynthesis [49]. One factor that influences the oxygen levels in the medium is the agitation rate. By increasing the agitation rate, the dissolved oxygen in the medium increases, which enhances the growth and lipid content [45]. The effect of different agitation speeds on growth, lipid, and carotenoid production by Rhodotorula glutinis is represented in Table 1 .

Increasing agitation speed from $150 \mathrm{rpm}$ to 200 and 220 increased the growth rate significantly by around $16 \%(p=0.011)$, while no differences in biomass were observed between $200 \mathrm{rpm}$ and $220 \mathrm{rpm}$. The highest growth efficiency was observed with low agitation speed around $48.3 \%$, whereas, the highest agitation speed decreased growth efficiency to $43.9 \%$ after 3 days, shown in Table 1 and Table S7. The decrease in the growth efficiency with increasing agitation speed may be related to the unbearable shear force, which caused the cell damage [50]. Or it may be due to the depression of the metabolic activity as reported by Vlaev et al. [51]. The authors found that the effect of the high agitation speed on Sporobolomyces salmonicolor AL was attributed to depressed metabolic activity at the evolving dissolved oxygen tension rather than to the direct effect of hydrodynamics.

Similarly, lipid production by $R$. glutinis was enhanced significantly with increasing agitation up to $200 \mathrm{rpm}$, which showed around 30\% ( $p=0.000), 35 \%(p=0.005)$, and $32.6 \%(p=0.007)$ compared with 180, 200, and $220 \mathrm{rpm}$, respectively, shown in Table 1 and Table S7. The highest TL-RP was observed at $200 \mathrm{rpm}$, around $48.8 \%$, after 6 days. R. glutinis is an aerobic organism in which oxygen is a critical factor for enhancing biomass and lipid production, thus that increasing agitation speed to the suitable speed $200 \mathrm{rpm}$ led to lipid and biomass production enhancement. Other studies reported similar results regarding the enhancement role of high aeration or agitation on lipid and biomass production. The optimum agitation rate for the production of single-cell oil (SCO) by R. glutinis was $180 \mathrm{rpm}$ [52].

In addition, El-Fadaly et al. [53] investigated the effect of agitation speed on the SCO production by C. curvatus NRRLY-1511 and found that the maximum dry cell mass and lipid yield were obtained at $200 \mathrm{rpm}$. Milkessa et al. [45] observed the optimum agitation speed for the maximum lipid production by R. kratochvilovae SY89 at $225 \mathrm{rpm}$.

Additionally, the carotenoid production increased with a gradual increase of agitation speed from $150 \mathrm{rpm}$ to $200 \mathrm{rpm}$, which showed around a 23.6\% increased (insignificant $p>0.05$ ), while the further agitation speed showed no further increase in total pigment. Contrasting to the low agitation speed, the carotenoid relative productivity (Car-RP) of 200, and $220 \mathrm{rpm}$ at the $6^{\text {th }}$ day was almost the same like the $3^{\text {rd }}$ day, and this may be related to the reduction in the lipid accumulation with $220 \mathrm{rpm}$ and 
the excess of dissolved oxygen supply in case of 200 and $220 \mathrm{rpm}$ (Table 1). The multivariate test showed the significance only with DCW and TL with low agitation speed $150 \mathrm{rpm}(p<0.008)$ after 3 and 6 days (Table S8).

When the growth rate was expressed as a function of phosphate concentration, the growth medium increased, and it was observed that both DCW and DCW-Y were enhanced with the further increase of phosphate, Table 1. Around an $11 \%(p=0.001)$ increase was noticed when the DCW of $\mathrm{C} / p$ $527(0.5 \mathrm{~g} / \mathrm{L})$ and C/P $59(4.5 \mathrm{~g} / \mathrm{L})$ after 6 days were compared. Statistically, the dry cell weight of the highest phosphate concentrations $(4.5 \mathrm{~g} / \mathrm{L})$ treatment was significant with the other lower concentration $(p<0.01)$, shown in Table 1 and Table S9. As has been mentioned, when the yeast usually grows under nutrient-rich conditions, it contains around $4 \%-5 \%$ total phosphorus as $\mathrm{P}_{2} \mathrm{O}_{5}$, on a dry-weight basis [25]. This is why its presence in the growth media, with a reasonable supply, fits with the available nutrient content in the growth media and will positively affect the growth rate and glucose assimilation.

On the contrary, both total lipid and lipid relative productivity (TL-RP) were decreased with increasing phosphorus concentration in the growth medium, the highest TL-RP was achieved at C/P 527 $(0.5 \mathrm{~g} / \mathrm{L}) 52.1 \%$ (TL was $5.3 \pm 0.08 \mathrm{~g} / \mathrm{L})$, which represents around a $39 \%(p=0.000)$ and $63 \%(p=0.001)$ increase compared with C/P $88(3 \mathrm{~g} / \mathrm{L})(3.5 \pm 0.04 \mathrm{~g} / \mathrm{L} \mathrm{TL})$ and C/P $59(4.5 \mathrm{~g} / \mathrm{L})(2.3 \pm 0.06 \mathrm{~g} / \mathrm{L} \mathrm{TL})$ after 6 days. The statistical analysis revealed that the $4.5 \mathrm{~g} / \mathrm{L}$ phosphorus group was significant within all groups (Table 1 and Table S9). The enhancement role of phosphorus deficiency to fat accumulation in yeast cells was reported earlier by Schulze [25] when different starter phosphorus was supplied in the form of ammonium pyrophosphate to the yeast continuously growing in the bioreactor. A reverse relationship between fat content and protein content depending on phosphorus concentration was observed, as the high phosphorus concentration led to rapid yeast reproduction, producing cells rich in protein and low in fat. An interesting recent study [54] emphasized that the role of phosphorus deficiency for enhancing lipid production by $R$. toruloide depends on the multi-omic study. The results showed that the cells accumulated less than $10 \%$ lipid when growing on nutrient-rich media, and the cellular lipid increased significantly to above $40 \%$ when the studied yeast was grown on phosphate deficient condition.

The carotenoid production under different starter phosphate concentration is represented in Table 1 and Table S9, where the increase of phosphate concentration in the growth media from $0.5 \mathrm{~g} / \mathrm{L}$ to $4.5 \mathrm{~g} / \mathrm{L}$ led to a significant increase in both volumetric and cellular pigment production by R. glutinis, which represented around a $37 \%(p=0.001)$ and $11 \%$ increase, respectively. The one-way ANOVA analysis showed that the $0.5 \mathrm{~g} / \mathrm{L}$ phosphorus group was statistically significant with all higher group only on the $6^{\text {th }}$ day $(p<0.025)$. The multivariate test showed the significant effect of the low C/P molar ratio on DCW. All C/P treatments were significant with TL ( $3^{\text {rd }}$ and $6^{\text {th }}$ day) and carotenoid $\left(6^{\text {th }}\right.$ day only), as shown in Table S10.

Notably, the yield of carotenoid was enhanced with increasing phosphate concentration in the growth media. These data indicated the role of phosphate to enhance the efficiency of glucose uptake from the growth media by the studied yeast strain and its further conversion to either biomass or carotenoid. Although several studies were conducted to study the effect of different culture condition on carotenoid production by red yeasts $[29,45,47,55-58]$, as far as is known, there is no study that investigated the effect of phosphate on carotenoid production by red oleaginous yeast until now. A similar study conducted on algae [59] reported that both growth, chlorophyll, and beta carotene were significantly enhanced with increasing phosphorus concentration in the growth medium of Dunaliella salina. On the other hand, a study carried out on marine microalga Nannochloropsis gaditan observed the enhancement of carotenoid production under both phosphate and sulfur deficiency [60].

All the above-mentioned experiments showed the domination of carotenoid synthesis rate, yield, and cellular carotenoid on the $3^{\text {rd }}$ day while the highest yield of lipid was observed after the $6^{\text {th }}$ day. This result confirmed the reversible relationship between lipid and carotenoid production under high $\mathrm{C} / \mathrm{N}$ through the manipulation of the culture conditions. 
The Pearson correlation analysis (two-tailed) between the different studied factors-carbon sources, temperature, $\mathrm{pH}$, agitation speed, and $\mathrm{C} / \mathrm{P}$ molar ratio-and the different dependent variables of DCW, TL, and TP are represented at Supplementary Materials 2. The factors of carbon sources, temperature, $\mathrm{pH}, \mathrm{C} / \mathrm{P}$ molar ratios showed a significant correlation $(p<0.05)$ between the different dependent variables, which indicates their significance as a tool for enhancing biomass, lipid, and carotenoid production by R. glutinis.

\subsubsection{Lipid and Carotenoid Profile of R. glutinis under Different Culture Conditions}

The variation of the fatty acid methyl esters and carotenoid profile produced by R. glutinis due to manipulation of culture conditions is represented in Table 2 and Figure 6, respectively.

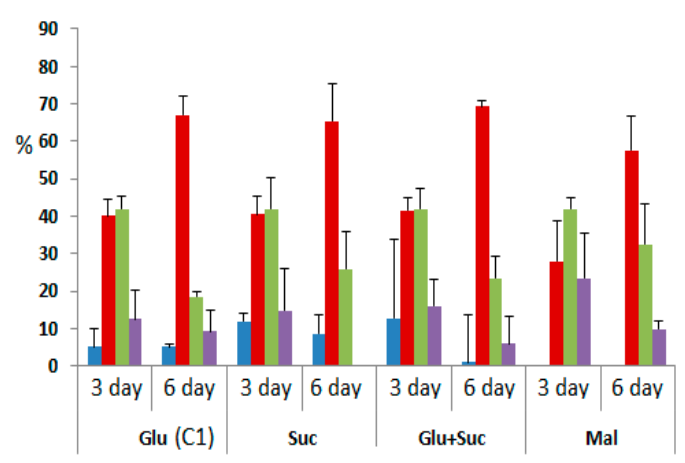

(a)

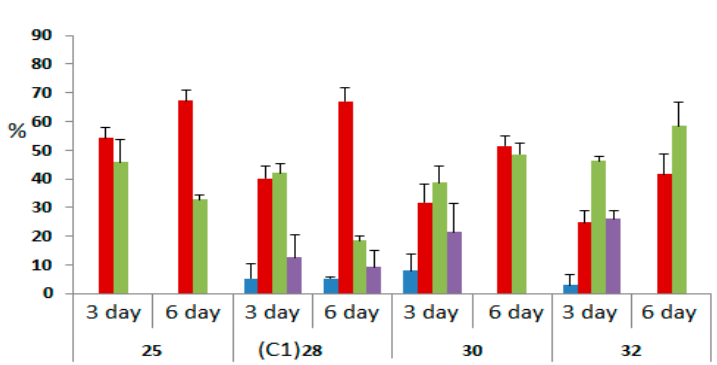

(c)

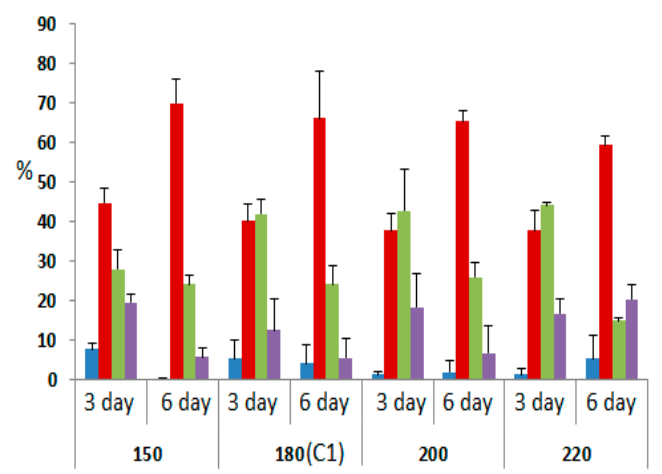

(b)

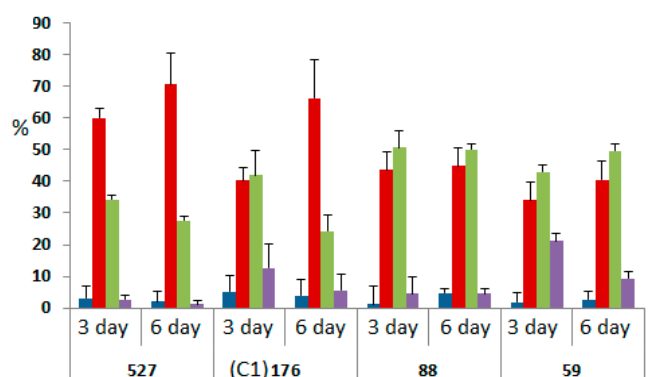

(d)

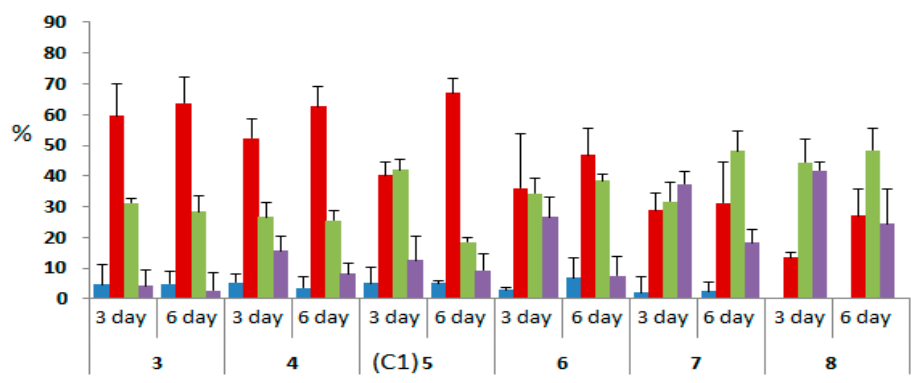

(e)

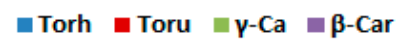

Figure 6. Identification and quantification of the individual carotenoid of $R$. glutinis as a response to different culture conditions using high-performance liquid chromatography (HPLC), the Y-axis represents the ratio of the individual carotenoid, $\mathrm{X}$-axis represents the factor groups ; (a) different carbon sources; Glu: Glucose, Suc: Sucrose, Gluc + Suc: Glucose + sucrose, Mal: Maltose. (b) Different agitation speed. (c) Different incubation temperatures. (d) Different initial C/P molar ratio. (e) Different $\mathrm{pH}$ degree. The data are the mean of two replicas, the standard deviation represented as the error bar. The significance was calculated by using the multivariate test and represented at Supplementary Materials 2. 
Table 2. The profile of fatty acid methyl esters (FAMES) of R. glutinis as a factor of culture conditions manipulation.

\begin{tabular}{|c|c|c|c|c|c|c|c|c|}
\hline Factor & & Time (Day) & C16:0 & C16:1 & C18:0 & C18:1 & C18:2 & C18:3 \\
\hline \multirow{4}{*}{$\begin{array}{l}\text { Carbon } \\
\text { sources }\end{array}$} & \multirow{2}{*}{ Glu C1 } & $3^{\mathrm{rd}}$ & $12.2 \pm 1.4$ & nd & $8.80 \pm 9.9$ & $68.8 \pm 5.7$ & $5.90 \pm 8.0$ & $4.30 \pm 8.5$ \\
\hline & & $6^{\text {th }}$ & $20.4 \pm 3.0$ & nd & $11.7 \pm 2.8$ & $48.8 \pm 7.1$ & $10.4 \pm 4.9$ & $8.70 \pm 3.1$ \\
\hline & Suc & $6^{\text {th }}$ & $17.1 \pm 2.0$ & nd & $2.40 \pm 1.4$ & $46.6 \pm 5.7$ & $9.10 \pm 5.0$ & $15.7 \pm 2.0$ \\
\hline & Glu+Suc & $3^{\text {rd }}$ & $7.20 \pm 4.0$ & nd & $5.10 \pm 5.0$ & $69.6 \pm 4.2$ & $13.5 \pm 7.1$ & $4.60 \pm 5.0$ \\
\hline \multirow{11}{*}{$\mathrm{pH}$} & \multirow{2}{*}{ Mal } & $3^{\text {rd }}$ & $8.40 \pm 3.50$ & nd & $15.3 \pm 4.2$ & $48.1 \pm 1.0$ & $12.7 \pm 13$ & $15.6 \pm 4.9$ \\
\hline & & $6^{\text {th }}$ & $10.1 \pm 8.0$ & nd & $6.10 \pm 6.2$ & $52.2 \pm 6.4$ & $21.1 \pm 9.2$ & $10.5 \pm 11$ \\
\hline & \multirow{2}{*}{3} & $3^{\mathrm{rd}}$ & $10.1 \pm 4.2$ & nd & $4.80 \pm 9.9$ & $60.7 \pm 3.5$ & $16.1 \pm 9.2$ & $8.40 \pm 11$ \\
\hline & & $6^{\text {th }}$ & $13.6 \pm 2.1$ & nd & $10.3 \pm 1.4$ & $49.3 \pm 9.2$ & $19.9 \pm 7.0$ & $6.90 \pm 2.8$ \\
\hline & $5 \mathrm{C} 1$ & $6^{\text {th }}$ & $20.4 \pm 3.0$ & nd & $11.7 \pm 2.8$ & $48.8 \pm 7.1$ & $10.4 \pm 4.9$ & $8.70 \pm 3.1$ \\
\hline & \multirow{2}{*}{6} & $3^{\text {rd }}$ & $14.9 \pm 4.5$ & $2.5 \pm 3.5$ & $3.50 \pm 3.7$ & $64.1 \pm 4.5$ & $12.0 \pm 3.0$ & $3.00 \pm 4.7$ \\
\hline & & $6^{\text {th }}$ & $20.3 \pm 4.4$ & $2.3 \pm 4.8$ & $6.70 \pm 3.6$ & $48.4 \pm 3.0$ & $11.4 \pm 4.3$ & $11.0 \pm 2.5$ \\
\hline & \multirow{2}{*}{7} & $3^{\mathrm{rd}}$ & $18.4 \pm 2.3$ & $1.0 \pm 2.6$ & $1.60 \pm 2.2$ & $57.6 \pm 3.0$ & $11.2 \pm 5.7$ & $10.2 \pm 6.7$ \\
\hline & & $6^{\text {th }}$ & $20.5 \pm 5.8$ & $3.1 \pm 3.3$ & $7.80 \pm 6.0$ & $46.3 \pm 3.9$ & $15.2 \pm 4.6$ & $7.20 \pm 4.6$ \\
\hline & \multirow{2}{*}{8} & $3^{\text {rd }}$ & $13.7 \pm 4.0$ & $1.3 \pm 1.4$ & $7.70 \pm 4.7$ & $58.0 \pm 5.2$ & $17.8 \pm 4.2$ & $1.40 \pm 3.3$ \\
\hline & & $6^{\text {th }}$ & $24.5 \pm 4.9$ & nd & $12.0 \pm 2.4$ & $44.0 \pm 3.1$ & $14.3 \pm 4.0$ & $5.30 \pm 5.1$ \\
\hline \multirow{2}{*}{$\operatorname{Temp}\left({ }^{\circ} \mathrm{C}\right)$} & \multirow{2}{*}{32} & $3^{\text {rd }}$ & $17.4 \pm 3.2$ & nd & $9.40 \pm 0.7$ & $59.8 \pm 2.1$ & $11.1 \pm 7.1$ & $2.20 \pm 10$ \\
\hline & & $6^{\text {th }}$ & $25.0 \pm 5.7$ & nd & $12.5 \pm 2.1$ & $45.7 \pm 9.2$ & $10.2 \pm 7.8$ & $6.50 \pm 2.8$ \\
\hline \multirow{8}{*}{$\begin{array}{l}\text { Agitation } \\
\text { (rpm) }\end{array}$} & \multirow{2}{*}{150} & $3^{\text {rd }}$ & $7.10 \pm 2.10$ & nd & $6.40 \pm 5.0$ & $69.5 \pm 11.0$ & $10.9 \pm 2.8$ & $6.10 \pm 8.5$ \\
\hline & & $6^{\text {th }}$ & $21.2 \pm 10.0$ & nd & $8.40 \pm 1.0$ & $54.3 \pm 1.0$ & $10.1 \pm 8.5$ & $5.80 \pm 5.7$ \\
\hline & \multirow{2}{*}{$180 \mathrm{C} 1$} & $3^{\text {rd }}$ & $12.2 \pm 1.4$ & nd & $8.80 \pm 10$ & $68.8 \pm 5.7$ & $5.90 \pm 8.0$ & $4.30 \pm 8.5$ \\
\hline & & $6^{\text {th }}$ & $20.4 \pm 3.0$ & nd & $11.7 \pm 3.0$ & $48.8 \pm 7.1$ & $10.4 \pm 4.9$ & $8.70 \pm 3.1$ \\
\hline & \multirow{2}{*}{200} & $3^{\text {rd }}$ & $10.2 \pm 1.4$ & nd & $5.70 \pm 4.0$ & $60.8 \pm 12$ & $12.1 \pm 6.4$ & $11.2 \pm 5.7$ \\
\hline & & $6^{\text {th }}$ & $14.2 \pm 3.5$ & nd & $5.80 \pm 2.0$ & $45.9 \pm 2.1$ & $20.3 \pm 6.3$ & $13.7 \pm 7.0$ \\
\hline & \multirow{2}{*}{220} & $3^{\text {rd }}$ & $10.7 \pm 1.0$ & nd & $5.20 \pm 8.0$ & $56.8 \pm 5.0$ & $16.4 \pm 7.1$ & $10.9 \pm 9.9$ \\
\hline & & $6^{\text {th }}$ & $15.3 \pm 5.0$ & nd & $9.10 \pm 9.0$ & $46.6 \pm 9.2$ & $21.7 \pm 7.5$ & $7.30 \pm 2.9$ \\
\hline & 527 & $3^{\text {rd }}$ & $15.4 \pm 5.0$ & nd & $3.40 \pm 3.2$ & $69.8 \pm 13$ & $7.20 \pm 14$ & $4.20 \pm 7.9$ \\
\hline & 527 & $6^{\text {th }}$ & $19.7 \pm 4.9$ & $0.90 \pm 0.71$ & $3.10 \pm 1.3$ & $59.6 \pm 4.2$ & $12.1 \pm 2.3$ & $4.60 \pm 2.1$ \\
\hline & $176 C 1$ & $3^{\text {rd }}$ & $12.2 \pm 1.4$ & nd & $8.80 \pm 10$ & $68.8 \pm 5.7$ & $5.90 \pm 8.0$ & $4.30 \pm 8.5$ \\
\hline $\mathrm{C} / \mathrm{P}$ & $1 / 6 C_{1}$ & $6^{\text {th }}$ & $20.4 \pm 3.0$ & nd & $11.7 \pm 3.0$ & $48.8 \pm 7.1$ & $10.4 \pm 4.9$ & $8.70 \pm 3.1$ \\
\hline & 80 & $3^{\text {rd }}$ & $16.7 \pm 6.4$ & $1.0 \pm 4.5$ & $8.90 \pm 1.6$ & $60.1 \pm 3.8$ & $11.3 \pm 7.1$ & $2.00 \pm 4.9$ \\
\hline & 88 & $6^{\text {th }}$ & $15.1 \pm 7.0$ & $3.0 \pm 1.1$ & $10.2 \pm 3.0$ & $44.6 \pm 2.5$ & $17.0 \pm 7.1$ & $10.0 \pm 6.2$ \\
\hline
\end{tabular}

The data are the mean of three separate biological samples $( \pm \mathrm{SD})$. nd means not detected. The result of the multivariate test to compare between different dependent variables under different culture conditions is represented at Supplementary Materials 2. 
Looking to the carotenoid profile in Figure $6 \mathrm{a}$ as a response to different carbon source treatments, torulene was dominant with a ratio of more than $65 \%$ with glucose, sucrose, and a combination of glucose and sucrose. Using maltose reduce the torulene significantly to $57 \%(p=0.004)$ to the favour of $\gamma$-carotene $32.5 \%$. Shifting the carotenogenesis pathway toward torulene accumulation was also observed with Elbana et al. [29] when R. glutinis var. glutinis was grown on sucrose as a sole carbon source. The statistical analysis showed a significant difference in the torularhodin and $\gamma$-carotene ratio of glucose sets with other carbon sources treatments $(p<0.029)$, while the torulene and $\beta$-carotene ratio of glucose sets were only significant with maltose sets $(p<0.006)$. On the other hand, the lipid profile responded similarly to the different carbon sources except with maltose. Using glucose, sucrose, and glu+suc as a carbon source led to the dominance of oleic acid on the $3^{\text {rd }}$ day, with $68.8 \%, 61.3 \%$, and $69.6 \%$, respectively, which was reduced to favor linoleic acid (C18:2) with further incubation. The oleic acid ratio of glucose treatment was significant with the oleic acid ratio of sucrose $(p=0.000)$, and maltose $(p=0.000)$ treatments, and not significant with the Glu+suc treatment $(p>0.05)$ on the $3^{\text {rd }}$ day, while the further incubation caused significant differences between all treatments $(p=0.000)$ (Supplementary Materials 2). Although the total lipid was greatly reduced when maltose was used as a sole carbon source, its lipid profile showed the dominance of polyunsaturated fatty acid compared with the other carbon sources treatments, Table 2. Worthy to note, the lipid profile of the studied yeast with glu + suc and maltose as a carbon source after 3 and 6 days, respectively, was considered as a suitable source for human dietary consumption due to the domination of unsaturated fatty acids compared with other treatments.

As a factor of different $\mathrm{pH}$ treatments, the carotenoid profile showed the dominance of torulene at low $\mathrm{pH}$, above $58 \%$, then it decreased gradually with increasing $\mathrm{pH}$ to alkalinity in favor of $\gamma$-carotene, showing around a $36.8 \%(p=0.000)$ decrease in torulene, and around a $40 \%$ increase in the $\beta$-carotene and $\gamma$-carotene ratios $(p=0.000)$. When the carotenoid profile of $\mathrm{pH} 8$ and $\mathrm{pH} 3$ treatments were compared (Figure 6e and Supplementary Materials 2), C18:1 was the dominant fatty acid overall, but the pattern of the fatty acid profile was slightly variable with different $\mathrm{pH}$ degrees. The highest ratio of oleic acid was observed after 3 days with acidic $\mathrm{pH}(3-6)$, above $64 \%$, while the alkaline $\mathrm{pH}$ $(7,8)$ showed an oleic acid ratio below $58 \%$ on the $3^{\text {rd }}$ day. The statistical analysis showed significant differences between the oleic acid ratio of the $\mathrm{pH} 3$ treatment and other treatments on the $3^{\text {rd }}$ day $(p<0.001)$. The further incubation led to a decrease in the oleic acid ratio to be between $49 \%$ and $44 \%$ with different $\mathrm{pH}$ treatments and insignificant when the $\mathrm{pH} 3$ oleic acid ratio compared with $\mathrm{pH} 4,5$, and $6(p>0.05)$. Remarkably, the highest ratio of polyunsaturated fatty acid was observed at a low pH of 4 and 3, which counted above $30 \%$ of the total fatty acid on the $6^{\text {th }}$ day and it was statistically significant with most $\mathrm{pH}$ treatments compared with $\mathrm{pH} 3(p<0.009)$, as shown in Table 2 and Supplementary Materials 2. This result indicates the possibility of increasing the nutritional value of the lipid produced by the studied yeast strain by adjusting the initial $\mathrm{pH}$ degree. Increasing torulene and the oleic acid ratio at low acidic $\mathrm{pH}$ was also observed when $R$. glutinis was grown on the culture medium with glycerol and deproteinized potato wastewater at $\mathrm{pH} 3$ [61].

Additionally, the temperature factor showed an alteration in the profile of fatty acids. The polyunsaturated fatty acids after 3 days were above $35 \%$ at $25{ }^{\circ} \mathrm{C}$, which represented around twice the ratio at the other temperature groups, Table 2 . The higher temperatures showed the dominance of oleic acid even though a slight increase in the saturated fatty acid around $2 \%$ and $8 \%$ was observed with the highest temperature treatment $\left(30^{\circ} \mathrm{C}\right.$ and $\left.32^{\circ} \mathrm{C}\right)$, respectively, on the $6^{\text {th }}$ day. The statistical results showed a significant difference between the oleic acid ratio of $25^{\circ} \mathrm{C}$ treatment and 30 and $32{ }^{\circ} \mathrm{C}$ treatments $\left(p=0.19, p=0.03\right.$, respectively) after the $3^{\text {rd }}$ day and the ratio of oleic acid of $25^{\circ} \mathrm{C}$ group became significant with the three other treatments at the end of incubation $(p<0.000)$. Whereas, the total polyunsaturated fatty acid was almost the same with a slight insignificant variation at the end of cultivation compared with $28^{\circ} \mathrm{C}$, as shown in Table 2, and Supplementary Materials 2. Regarding the fatty acid profile, the dominance of polyunsaturated fatty acid was also observed at the 
low-temperature degree when Lipomyces starkey was incubated at different temperatures 10, 20, and $30{ }^{\circ} \mathrm{C}[62]$.

While the carotenoid profile showed the dominance of torulene above $67 \%$ at $25^{\circ} \mathrm{C}$ and $28{ }^{\circ} \mathrm{C}$ at the $6^{\text {th }}$ day with gradual shifting toward $\gamma$-carotene when the temperature was increased to $30^{\circ} \mathrm{C}$ and $32{ }^{\circ} \mathrm{C}$, representing around a $15 \%(p=0.000)$ and $25 \%(p=0.001)$ decrease in torulene and $22 \%$ $(p=0.000)$ and $31 \%(p=0.000)$ increase in $\gamma$-carotene compared with $28{ }^{\circ} \mathrm{C}$, respectively, in Figure $6 \mathrm{c}$ and Supplementary Materials 2. A significant increase in torulerhodin at a low-temperature of $19^{\circ} \mathrm{C}$ was reported when Sporobolomyces ruberrimus was grown on glycerol under different temperatures [48]. This result showed the possibility of producing healthy oil with highly valuable carotenoid by R. glutinis when the low incubated temperature was considered.

The profile of fatty acids in respect to different agitation speeds showed the dominance of oleic acid for more than $68 \%$ with the lowest agitation speed 180 and $150 \mathrm{rpm}$ on the $3^{\text {rd }}$ day. While the highest agitation speeds of 200 and $220 \mathrm{rpm}$ showed around $60.8 \%$ and $56.8 \%$ oleic acid dominancy, respectively, on the $3^{\text {rd }}$ day. The oleic acid ratio was significant, with the highest agitation speed of $200(p=0.000)$ and $220 \mathrm{rpm}(p=0.000)$ compared with $150 \mathrm{rpm}$. Worthy to note, the polyunsaturated fatty acid, linolenic acid, increased by more than $12 \%$ when the agitation speed increased from 150 to $220 \mathrm{rpm}$ on the $6^{\text {th }}$ day, in Table 2 and Supplementary Materials 2 . In addition, the highest ratio of saturated fatty acid was observed at 150 and $180 \mathrm{rpm}$, which was statistically significant after 6 days with the highest agitation speed $(p<0.01)$.

The further increase of agitation speed decreased the saturated fatty acid around $7 \%$ to the favour of unsaturated fatty acid. The increase of unsaturated fatty acids may be related to the activation of desaturase enzymes, which are responsible for the formation of oleic acid, linoleic acid, and linolenic acid through consecutive series of desaturation steps as a response to increasing dissolved oxygen supply, which comes from the increasing agitation speed. Similar to our results, when Aspergillus oryzae was grown with different agitation speeds $(70,120$, and $170 \mathrm{rpm})$, the polyunsaturated fatty acid ratio in the lipid profile increased with $120 \mathrm{rpm}$ to be twice as much, compared with $70 \mathrm{rpm}$, and a further increase to $170 \mathrm{rpm}$, led to a decrease in linoleic acid of around 5\% compared with $120 \mathrm{rpm}$ [63]. While other studies carried on the algal strain Porphyridium cruentum [64] reported the opposite, as the unsaturation level of the fatty acid, especially the long-chain polyunsaturated fatty acid, was enhanced under low agitation speed. The differences in result may rely on the other factor variations like the strains and other culture conditions.

Davoli et al. [65] grown R. glutinis and Sporobolomyces roseus under different aeration regimes; the result showed a differential response in their carotenoid content. At higher aeration, the concentration of total carotenoids increased relative to the biomass and total fatty acids in $R$. glutinis, but the composition of carotenoids (torulene $>\beta$-carotene $>\gamma$-carotene $>$ torularhodin) remained unaltered. In contrast, $S$. roseus responded to enhanced aeration by a shift from the predominant $\beta$-carotene to torulene and torularhodin, indicating that the torulene production preferred the high aeration rate. This report is contrasting to our result, as the high agitation, $220 \mathrm{rpm}$, was favorable for $\gamma$-carotene and $\beta$-carotene accumulation over torulene production by $R$. glutinis, as the ratio of torulene produced at $220 \mathrm{rpm}$ decreased around 10\% compared with $150 \mathrm{rpm}$ (Figure 6b). The statistical analysis showed a significant variance between the distribution of different individual carotenoid as a response to different agitation speeds ( $p<0.05$, Supplementary Materials 2).

Finally, the different starter phosphate concentrations did not greatly affect the oleic and stearic acid content. It was observed that during the first 3 days oleic acid was dominant with a ratio range between $60 \%$ to $69 \%$ with all treatments $(p<0.002)$, when the oleic acid ratio of C/P 527 treatment compared with 88 and $59 \mathrm{C} / \mathrm{P}$ treatments after 3 days (Supplementary Materials 2), then decreased with further incubation to the favor of saturated fatty acid with high $\mathrm{C} / \mathrm{P}$ ratio, and polyunsaturated fatty acid with low $\mathrm{C} / \mathrm{P}$ ratio, although the difference was only around a $13 \%$ increase than the $527 \mathrm{C} / \mathrm{P}$ ratio, Table 2. 
Increasing $\mathrm{C} / \mathrm{P}$ ratio was accompanied with the domination of torulene over other carotenoid fractions, and decreasing significantly with decreasing C/P ratio from $70 \%$ at C/P 527 to $40 \%$ at $\mathrm{C} / \mathrm{P} 59$ $(p=0.000)$ with shifting the carotenoid production toward $\gamma$-carotene $(p=0.000)$, shown as Figure $6 \mathrm{~d}$ and Supplementary Materials 2.

\subsection{Effect of Different Metal Types and Concentrations on R. glutinis Growth, Lipid, and Carotenoid Production}

3.2.1. Microscopic Examination of Cell and Lipid Bodies Accumulation of R. glutinis under Different Metal Treatments

Differences in the cellular morphology and the lipid bodies accumulation after growing the yeast cells in media supplemented with different metal treatments, and their estimated corrected total cell fluorescence (CTCF) value is represented in Figure 7 and Figure S1. Changing the cultivation medium to medium with $\mathrm{C} / \mathrm{S}$ ratio 120 (C2), led to reducing lipid bodies numbers inside the cells compared with the above-described treatment (C1) (Figure 7a).

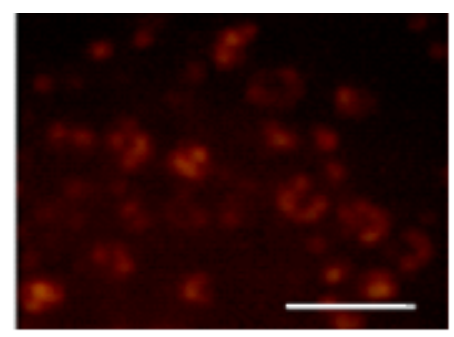

(a)

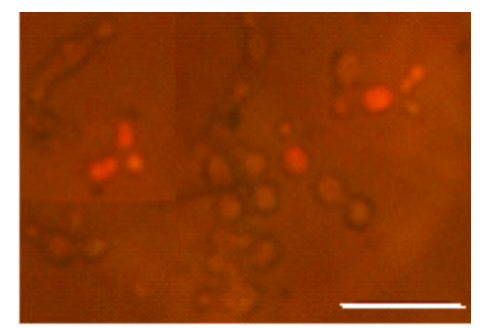

(d)

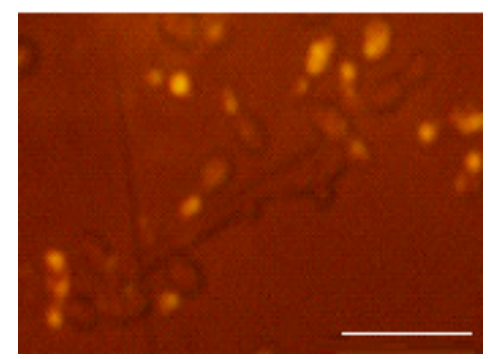

(g)

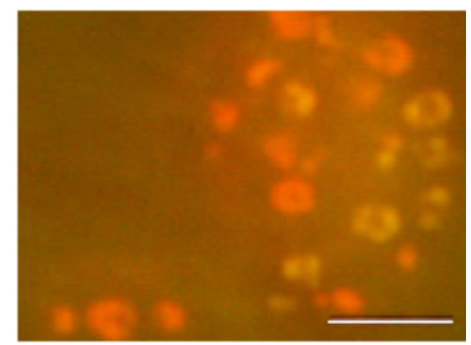

(b)

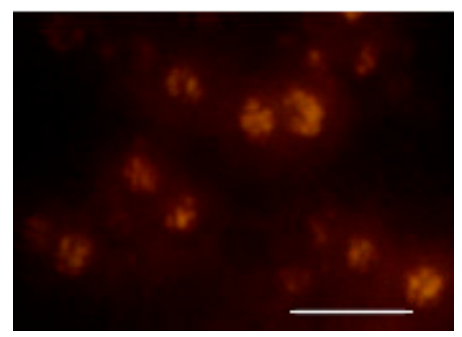

(e)

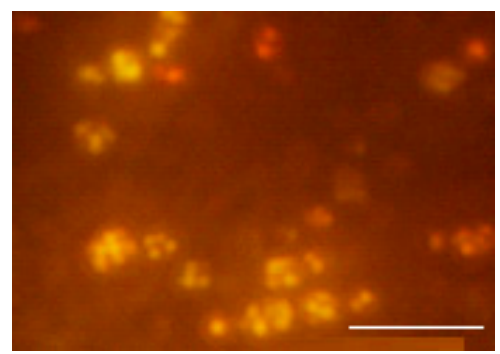

(h)

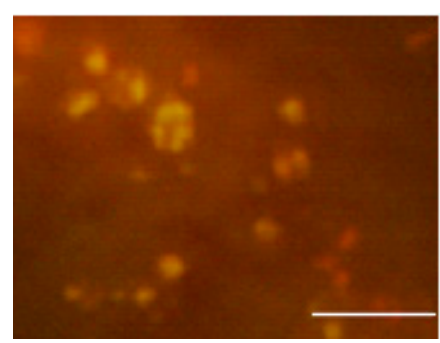

(c)

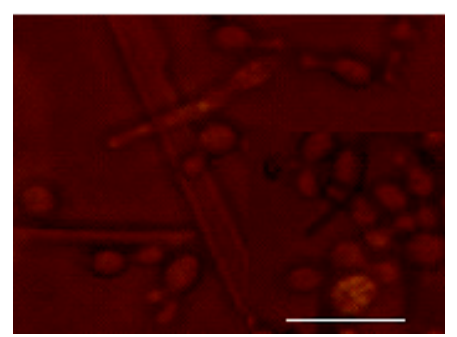

(f)

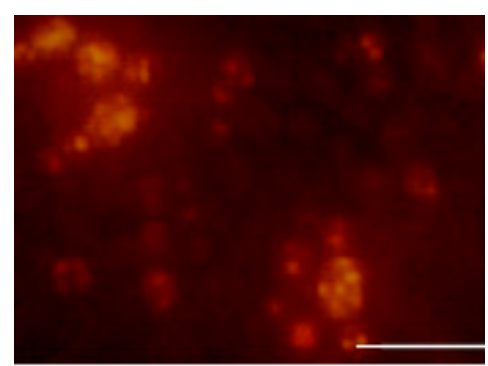

(i)

Figure 7. Cont. 


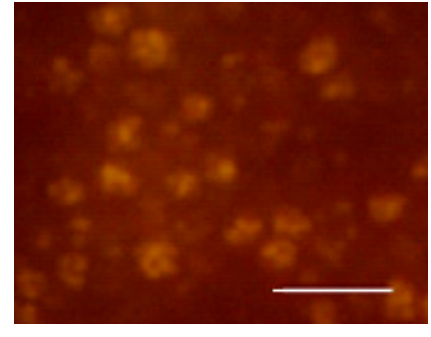

$(\mathbf{j})$

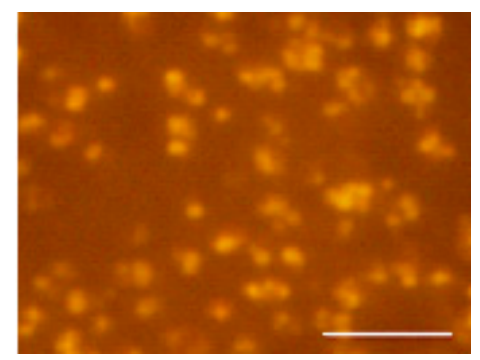

$(\mathbf{k})$

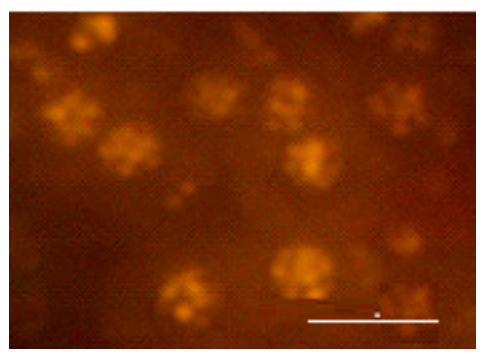

(1)

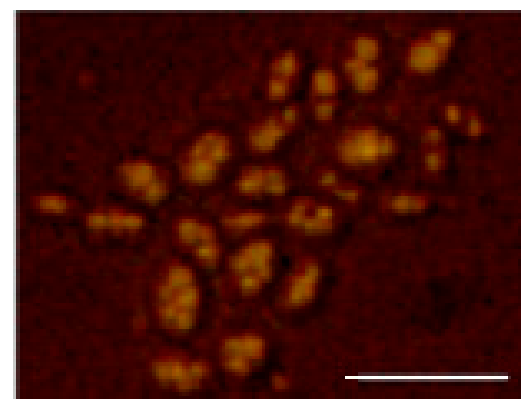

(m)

Figure 7. Fluorescence microscopy examination of Nile-red stained yeast cells after growing on medium supplemented with different concentration of heavy metal: (a) Control; (b) $\mathrm{CuSO}_{4} 0.1 \mathrm{mM}$; (c) $\mathrm{Zncl}_{2}$ $0.1 \mathrm{mM}$; (d) $\mathrm{ZnCl}_{2} 1 \mathrm{mM}$; (e) NiSO $40.1 \mathrm{mM}$; (f) NiSO $41 \mathrm{mM}$; (g) FeSO 0.1 mM; (h) Licl $0.1 \mathrm{mM}$; (i) LiCl $1 \mathrm{mM}$; (j) $\mathrm{MnCl}_{2} 0.1 \mathrm{mM}$; (k) $\mathrm{MnCl}_{2} 1 \mathrm{mM}$; (l) $\mathrm{BaCl}_{2} 0.1 \mathrm{mM}$; (m) $\mathrm{BaCl}_{2} 1 \mathrm{mM}$. The magnification bar is equal to $10 \mu \mathrm{m}$.

The effect of metal supplementation is varied depending on the concentrations and the type of metal stress. Usually, the low concentration of $\mathrm{CuSO}_{4} 0.1 \mathrm{mM}$ (Figure $7 \mathrm{~b}$ ), $\mathrm{ZnCl}_{2} 0.1 \mathrm{mM}$ (Figure $7 \mathrm{c}$ ), and NiSO4 $0.1 \mathrm{mM}$ (Figure 7e) showed a varied number of lipid bodies, the CTCF value of those metals was slightly more or similar to the CTCF of the control (Figure S1f, Supplementary Materials 1). However, increasing the previously mentioned metal to $1 \mathrm{mM}$ led to a reduction in both cell size and lipid bodies and CTCF value, besides the appearance of the pseudo mycelium, which represented elongated cells that remained attached to the mother cells as observed with $\mathrm{NiSO}_{4} 1 \mathrm{mM}$, which showed the lowest CTCF value (Figure $7 \mathrm{f}$ and Figure S1f). Mainly, the blue fluorescence was used for the examination of Nile red-stained lipid bodies, but the white light was used shortly with blue fluorescence at the time of imaging to detect the shape of the cells. $0.1 \mathrm{mM} \mathrm{FeSO}_{4}$ was affected on lipid accumulation as the cells kept a small oval-shape with the appearance of psedumycelium that carried small buddy cells on it. In contrast to the pseudomycelium formed with $\mathrm{NiSO}_{4} 1 \mathrm{mM}$, there were no lipid bodies observed at all inside the psedumycelium of the iron treatment and the buddy cells carried on it (Figure 7g).

While using barium (Figure 7l,m) and lithium (Figure 7h,i) either in low or high concentrations, showed an observable increase in the cell size, lipid bodies as well as CTCF value, specifically with $\mathrm{BaCl}_{2} 0.1 \mathrm{mM}$, which showed the highest CTCF value (Figure S1f). Regarding the microscopic analysis, the $0.1 \mathrm{mM}$ and $1 \mathrm{mM} \mathrm{BaCl} 2$ could enhance the production of lipid by R. glutinis, even increasing the $\mathrm{C} / \mathrm{S}$ ratio in the culture medium.

\subsubsection{Effect of Different Metal Stress on Lipid and Carotenoid Production by R. glutinis}

Metals can have a significant effect on the enzymatic activity of different biological pathways inside the microbial cells. The studied yeast strain showed a variable response in growth, lipid, and carotenoid production toward different metal treatments, as shown in Figure 8. The growth rate of R. glutinis reduced significantly after exposure to $\mathrm{FeSO}_{4} 0.1 \mathrm{mM}(p=0.000), \mathrm{FeCl}_{3} 0.1 \mathrm{mM}(p=0.000)$, 
$\mathrm{CuSO}_{4} 0.1 \mathrm{mM}(p=0.000), \mathrm{MnCl}_{2} 1 \mathrm{mM}(p=0.000), \mathrm{NiSO}_{4} 1 \mathrm{mM}(p=0.003)$, and $\mathrm{ZnCl}_{2} 0.1$ and $1 \mathrm{mM}$ $(p=0.000)$. While other metal treatments were showed insignificant DCW increase like $\mathrm{BaCl}_{2} 0.1 \mathrm{mM}$, $\mathrm{NiSO}_{4} 0.1 \mathrm{mM}$ and $\mathrm{LiCl}$ compared with control, Figure 8a.

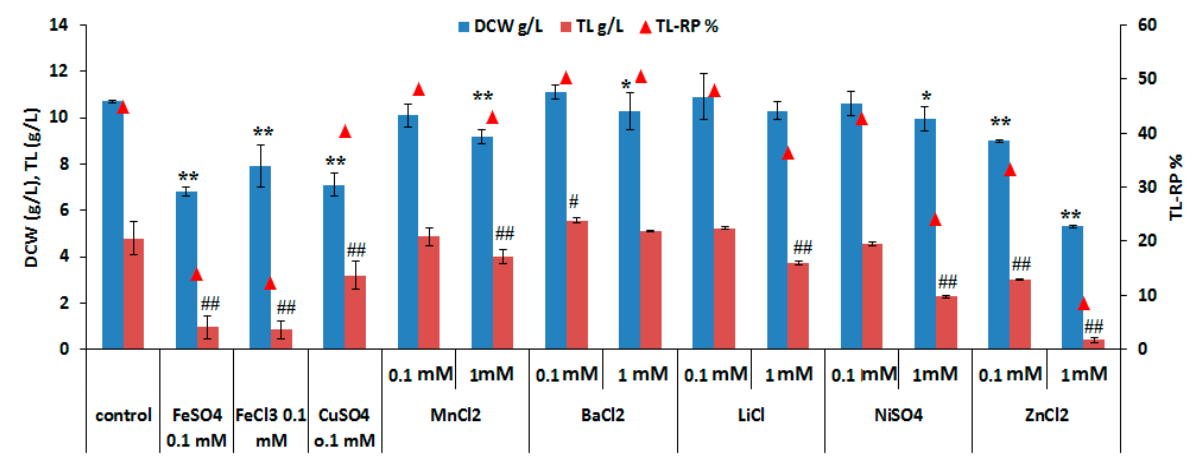

(a)

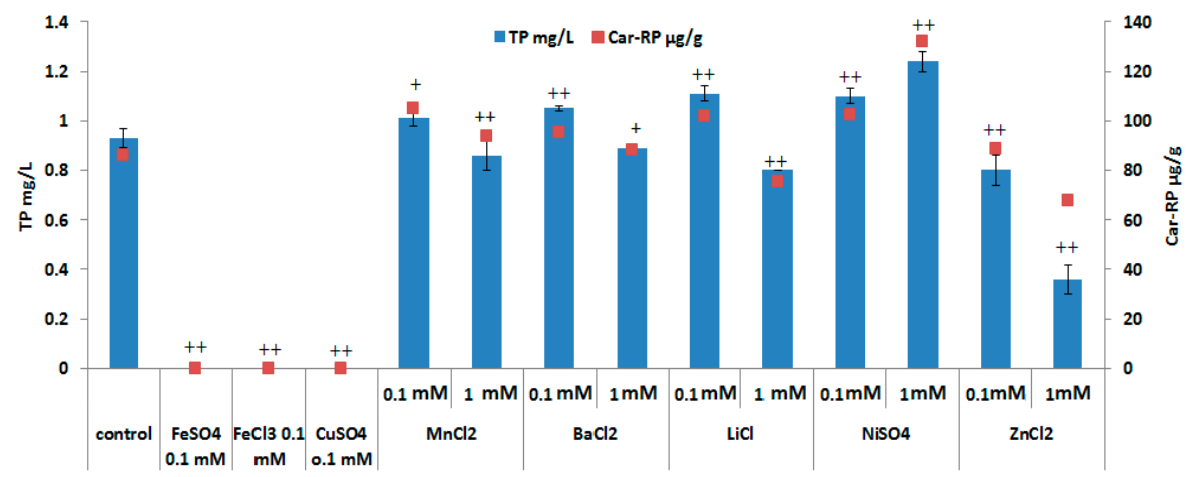

(b)

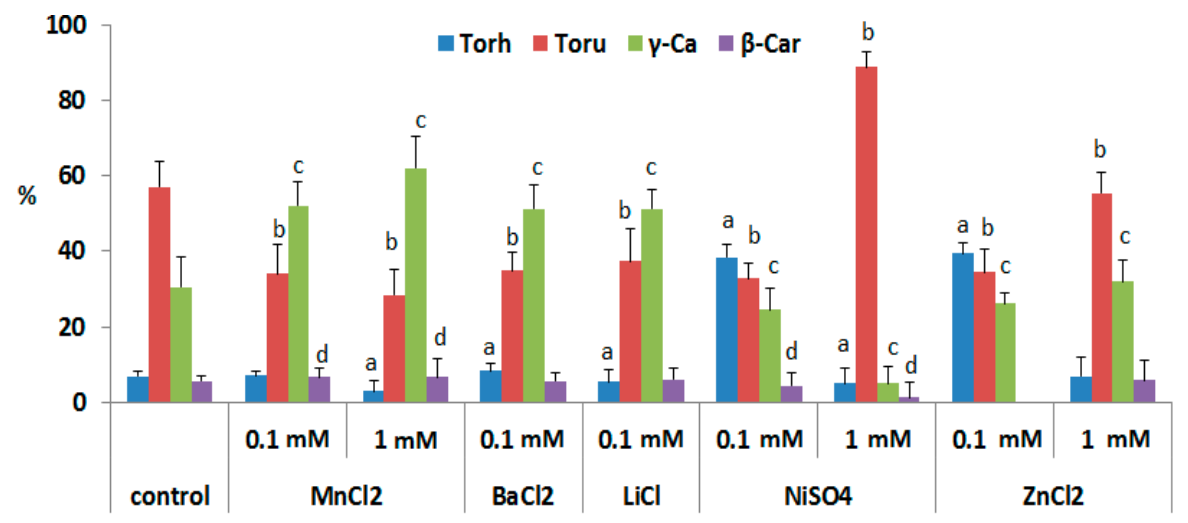

(c)

Figure 8. Effect of different metal ion stress on growth, lipid, and carotenoid production of R. glutinis on the $6^{\text {th }}$ day: (a) Effects of different metal ion stress on dry cell weight (DCW), total lipid (TL), and total lipid-relative productivity (TL-RP). ${ }^{*}$ and ${ }^{* *}$ mean DCW of metal ion treated groups are statistically significant with DCW of control group $p<0.05$ and $p<0.01$, respectively. \# and \#\# mean TL of metal ion treated groups are statistically significant with TL of control group $p<0.05$ and $p<0.01$, respectively; (b) effects of different metal ion stress on TP and Car-RP. + and ++ mean TP of metal ion treated groups are statistically significant with TP of control group $p<0.05$ and $p<0.01$, respectively; (c) individual carotenoid profile of $R$. glutinis after treatment with different metal ion stress, the same letters means the individual carotenoids were statistically significant with its candidate at the control group $(p<0.05)$. The data are the mean of three separate biological samples. The error bar represents the standard deviation. 
Focusing on lipid production under different metal stress, some metal reduced the lipid production to more than $80 \%$ like $\mathrm{ZnCl}_{2} 1 \mathrm{mM}(p=0.000), \mathrm{FeSO}_{4} 0.1 \mathrm{mM}(p=0.000)$, and $\mathrm{FeCl}_{3} 0.1 \mathrm{mM}(p=0.000)$. On the other hand, some metals enhanced cellular lipid accumulation such as $\mathrm{BaCl}_{2}(0.1 \mathrm{mM})(p=0.05)$, $\mathrm{MnCl}_{2}(p>0.05)$, and $\mathrm{LiCl}(p>0.05)$. The cellular lipid increased significantly from $44.9 \%$ (Control) to $50 \%$ with $\mathrm{BaCl}_{2}$ supplementation, Figure $8 \mathrm{a}$.

This points to the enhancement role of barium, manganese, and lithium-ion for lipid production by the studied yeast strain, even the low $\mathrm{C} / \mathrm{S}$ ratio. Contrasting to the few studies, which investigated the effect of metal stress on lipogenesis of yeasts, several studies were carried out on algae.

A recent study investigated the effect of different metal stress on the growth and lipid production by Chlorella minutissima UTEX 2341 [27]. All the studied metals showed a considerable increase in the total lipid production by C. minutissima UTEX 2341, $6 \mathrm{mM} \mathrm{Zn}, 0.4$ and $1 \mathrm{mM} \mathrm{Cu}$ significantly increased the algae lipid content by $18.30 \%, 21.07 \%, 19.87 \%$, respectively.

The effect of metals stress on R. glutinis carotenoid production was also detected, Figure $8 \mathrm{~b}$. Surprisingly, some metals like $0.1 \mathrm{mM}$ iron and copper salts blocked the carotenoid pathway, which reflected as the disappearance of the distinct red or radish color of the cells and appeared as a white biomass. Generally, metals like $0.1 \mathrm{mM}$ of $\mathrm{MnCl}_{2}, \mathrm{BaCl}_{2}, \mathrm{LiCl}$, and $\mathrm{NiSO}_{4}$ significantly increased carotenoid production of $R$. glutinis from $0.93 \mathrm{mg} / \mathrm{L}$ to $1.01(p=0.01), 1.05(p=0.001), 1.11(p=0.000)$, and $1.09(p=0.009) \mathrm{mg} / \mathrm{L}$, respectively. In addition, cellular carotenoid increased from 86.2 to 100.3 , 95.1, 101.7, and $102.4 \mu \mathrm{g} / \mathrm{g}$, respectively. However, the further increase of the former metals to $1 \mathrm{mM}$ led to a decrease of both cellular and total carotenoid significantly $(p<0.05)$ except with nickel sulfate, which increased cellular carotenoid to $132 \mu \mathrm{g} / \mathrm{g}$ and represented around 53\% increase than the control.

The previously reported studies of the effect of metal ion on the carotenoid productivity by red yeasts stated the enhancement role of metal ion on carotenogenesis $[24,29,30]$. The enhancement role of nickel sulfate on the carotenogenesis pathway of red oleaginous yeasts was not reported before. While other metals like $\mathrm{Ba}, \mathrm{Zn}, \mathrm{Fe}, \mathrm{Cu}$, and $\mathrm{Mn}$ were reported to enhance carotenoid production by Rhodotorula mutant 32 [30]. In addition, Elbana et al. [29] stated a similar result for the enhancing role of $\mathrm{Fe}, \mathrm{Zn}, \mathrm{Cu}$, and $\mathrm{Mn}$ on the carotenoid production by $\mathrm{R}$. glutinis var. glutinis. While our results showed the inhibitory role of iron and copper on carotenoid production by R. glutinis, these differences may be mainly related to the genus sensitivity to the metal stress. The individual carotenoid profile of R. glutinis as a response factor to different metal treatments is represented in Figure 8c. The control groups detected the dominance of torulene $63 \%$, followed by $\gamma$-carotene $30 \%$. The addition of $\mathrm{Mn}^{+2}$, $\mathrm{Ba}^{+2}$, and $\mathrm{Li}^{+}$led to enhance the production of $\gamma$-carotene significantly over torulene. The $\gamma$-carotene: Torulene ratio for $1 \mathrm{mM} \mathrm{Mn}^{+2}, 1 \mathrm{mM} \mathrm{Ba}^{+2}$, and $1 \mathrm{mM} \mathrm{Li}^{+1}$ were $62: 28,50: 37$, and 50:44, respectively. While $1 \mathrm{mM} \mathrm{NiSO}_{4}$ and $0.1 \mathrm{mM} \mathrm{ZnCl}_{2}$ increased torulene significantly to $88.9 \%(p=0.000)$ and $69.9 \%$ $(p=0.000)$, respectively.

R. glutinis var. glutinis showed the dominance of torulene when different heavy metal was introduced to the cultured media, the highest ratio observed with $\mathrm{MnSO}_{4}(80 \%)$, while the lowest ratio was observed with $\mathrm{FeSO}_{4}(56 \%)$ [29]. On the other hand, $\beta$-carotene was dominant when $\mathrm{FeSO}_{4}$, $\mathrm{CuSO}_{4}, \mathrm{MnSO}_{4}, \mathrm{BaCl}_{2}$, and $\mathrm{ZnSO}_{4}$ were introduced to the culture media of R. glutinis [30].

The response of the fatty acid profile to the different metal treatment was exciting (Table 3). Iron and copper supply to the culture media were led to reducing polyunsaturated fatty acid for the favor of saturated fatty acid; palmitic acid recorded the highest ratio $31 \%$ with $0.1 \mathrm{mM} \mathrm{CuSO}_{4}(p=0.000)$. On the other hand, $\mathrm{MnCl} 2, \mathrm{BaCl} 2$ and $\mathrm{LiCl}$ enhance the production of unsaturated fatty acid significantly $(p<0.001)$, especially polyunsaturated fatty acid on the favor of oleic acid, whereas there was no alteration was observed with the profile of saturated fatty acid compared with the control.

This result indicated that the addition of low concentration of either $\mathrm{MnCl}_{2}, \mathrm{BaCl}_{2}$, and $\mathrm{LiCl}$ to the growth media could enhance the production of colored fats riches with unsaturated fatty acid, especially linolenic acid and linoleic acid, Table 3. 
Table 3. The lipid profile of R. glutinis after treatment with different heavy metal stress.

\begin{tabular}{|c|c|c|c|c|c|c|c|c|c|}
\hline \multicolumn{2}{|l|}{ Factor } & C12:0 & C14:0 & C16:0 & C16:1 & C18:0 & C18:1 & C18:2 & C18:3 \\
\hline \multicolumn{2}{|l|}{ Control } & $0.1 \pm 0.2$ & $0.1 \pm 0.03$ & $13.2 \pm 6.2$ & $0.9 \pm 6.7$ & $5.8 \pm 5.6$ & $44.1 \pm 4.7$ & $29.3 \pm 4.0$ & $6.40 \pm 6.0$ \\
\hline \multicolumn{2}{|c|}{$\mathrm{FeSO}_{4} 0.1 \mathrm{mM}$} & $1.2 \pm 1.2 * *$ & $2.4 \pm 3.5^{* *}$ & $23.9 \pm 6.3^{* *}$ & $1.2 \pm 6.5^{*}$ & $6.0 \pm 1.9$ & $55.3 \pm 5.7$ ** & $9.60 \pm 2.1 * *$ & $0.40 \pm 6.9 * *$ \\
\hline \multicolumn{2}{|c|}{$\mathrm{FeCl}_{3} 0.1 \mathrm{mM}$} & $1.1 \pm 0.3^{* *}$ & $2.3 \pm 3.5^{* *}$ & $19.1 \pm 5.5^{* *}$ & $1.1 \pm 5.0^{*}$ & $7.5 \pm 5.1^{* *}$ & $56.2 \pm 6.7^{* *}$ & $11.0 \pm 6.7^{* *}$ & $1.70 \pm 3.3^{* *}$ \\
\hline \multicolumn{2}{|c|}{$\mathrm{CuSO}_{4} 0.1 \mathrm{mM}$} & $2.3 \pm 5.6^{* *}$ & $2.1 \pm 1.8^{* *}$ & $31.3 \pm 6.6^{* *}$ & $2.6 \pm 4.5^{* *}$ & $6.1 \pm 4.5$ & $38.5 \pm 6.6^{* *}$ & $14.5 \pm 5.9^{* *}$ & $2.60 \pm 7.5 * *$ \\
\hline \multicolumn{2}{|c|}{$\mathrm{CuCl}_{2} 0.1 \mathrm{mM}$} & $2.1 \pm 4.0^{* *}$ & $1.3 \pm 1.2 * *$ & $26.4 \pm 3.8^{* *}$ & $1.7 \pm 5.1^{* *}$ & $7.5 \pm 2.6^{* *}$ & $43.0 \pm 7.9$ ** & $14.8 \pm 8.9^{* *}$ & $3.10 \pm 4.0 * *$ \\
\hline \multirow{2}{*}{$\mathrm{MnCl}_{2}$} & $0.1 \mathrm{mM}$ & $0.1 \pm 0.8$ & $0.04 \pm 0.7^{* *}$ & $15.2 \pm 7.0^{* *}$ & $1.1 \pm 3.0^{*}$ & $3.4 \pm 6.6^{* *}$ & $29.5 \pm 3.6^{* *}$ & $36.3 \pm 5.8 * *$ & $14.3 \pm 6.7^{* *}$ \\
\hline & $1 \mathrm{mM}$ & $0.9 \pm 0.5^{* *}$ & $1.7 \pm 0.4 * *$ & $14.1 \pm 2.0^{*}$ & $1.1 \pm 2.0^{*}$ & $3.3 \pm 4.8^{* *}$ & $34.3 \pm 6.0$ ** & $34.7 \pm 5.0^{* *}$ & $9.90 \pm 3.9 * *$ \\
\hline \multirow{2}{*}{$\mathrm{BaCl}_{2}$} & $0.1 \mathrm{mM}$ & $0.5 \pm 0.5^{* *}$ & $0.1 \pm 0.2$ & $14.2 \pm 9.0^{*}$ & $1.1 \pm 1.8^{*}$ & $2.7 \pm 10^{* *}$ & $33.1 \pm 3.0$ ** & $35.5 \pm 3.8 * *$ & $12.7 \pm 8.4 * *$ \\
\hline & $1 \mathrm{mM}$ & $0.02 \pm 0.5^{* *}$ & $0.2 \pm 0.4^{*}$ & $15.2 \pm 1.5^{* *}$ & $1.2 \pm 4.0^{*}$ & $0.3 \pm 5.0^{* *}$ & $35.0 \pm 7.0$ ** & $35.7 \pm 2.8^{* *}$ & $12.3 \pm 4.0 * *$ \\
\hline \multirow{2}{*}{$\mathrm{LiCl}$} & $0.1 \mathrm{mM}$ & $0.04 \pm 0.3^{* *}$ & $0.1 \pm 1.5$ & $14.6 \pm 5.4^{*}$ & $1.2 \pm 4.5^{*}$ & $2.8 \pm 4.0 * *$ & $36.1 \pm 4.0$ ** & $35.1 \pm 6.8^{* *}$ & $10.0 \pm 5.5^{* *}$ \\
\hline & $1 \mathrm{mM}$ & nd & $0.1 \pm 0.7$ & $14.6 \pm 6.0^{*}$ & $1.2 \pm 5.0 *$ & $3.0 \pm 6.0 * *$ & $33.0 \pm 8.0$ ** & $36.3 \pm 3.9^{* *}$ & $11.9 \pm 6.8^{* *}$ \\
\hline \multirow{2}{*}{$\mathrm{NiSO}_{4}$} & $0.1 \mathrm{mM}$ & nd & $0.1 \pm 0.9$ & $12.3 \pm 5.0^{*}$ & $1.5 \pm 6.0^{* *}$ & $6.0 \pm 5.0$ & $60.7 \pm 3.8^{* *}$ & $16.2 \pm 2.0^{* *}$ & $3.20 \pm 5.5^{* *}$ \\
\hline & $1 \mathrm{mM}$ & $0.2 \pm 0.7^{* *}$ & $0.1 \pm 0.8$ & $13.6 \pm 8.0$ & $1.6 \pm 5.0^{* *}$ & $6.0 \pm 8.8$ & $60.0 \pm 7.0$ ** & $15.6 \pm 2.8^{* *}$ & $3.00 \pm 1.2 * *$ \\
\hline \multirow{2}{*}{$\mathrm{ZnCl}_{2}$} & $0.1 \mathrm{mM}$ & $0.1 \pm 1.3^{* *}$ & $0.04 \pm 0.1 * *$ & $13.2 \pm 5.7$ & $0.6 \pm 4.2 *$ & $11.2 \pm 4.2 * *$ & $40.5 \pm 6.6^{* *}$ & $27.8 \pm 2.1 *$ & $6.60 \pm 2.6$ \\
\hline & $1 \mathrm{mM}$ & $0.1 \pm 0.6^{* *}$ & $0.05 \pm .3 .0^{* *}$ & $13.2 \pm 4.2$ & $0.7 \pm 2.0 *$ & $12.2 \pm 2.1$ ** & $40.4 \pm 3.3^{* *}$ & $27.3 \pm 1.0 * *$ & $6.10 \pm 3.3$ \\
\hline
\end{tabular}

The data are the mean of two separate biological treatments \pm SD. nd; not detected. ${ }^{*}$ and ${ }^{* *}$ mean the different fatty acid methyl esters of metal ion treated groups are statistically significant with their candidate of the control group $p<0.05$ and $p<0.01$, respectively.

The addition of $\mathrm{NiSO}_{4}$ led to increasing oleic acid to $60 \%$, while the linoleic and linolenic ratio was $15.6 \%$ and $3 \%$, respectively, which represented only the half value compared with the control profile. The total unsaturated fatty acid produced by R. glutinis after adding $\mathrm{NiSO}_{4}$ was above $81 \%$.

\subsection{Fed-Batch Cultivation of R. glutinis Using Metallo-Sulfo-Phospho-Glucose Feeding Approach}

As an attempt to enhance the biomass production, which accumulated colored fats riches with the unsaturated fatty acid, a two feeding stage fed-batch cultivation strategy was applied. The strategy was dependent on conducting two groups: In the first group, the culture conditions were fixed along with the whole experiment (control group). Glucose solution (100 g/100 mL) was used for feeding during the accumulation phase. While the second group, the temperature and $\mathrm{pH}$ were changed with metal supplementation after the growth phase (optimized group) and a mixture from glucose-sulfur-phosphorous solution at a ratio of 100:0.2:0.2 (g/100 mL distilled water) was used for feeding during the accumulation phase. Both groups showed almost the same DCW, TL, and TP production by $R$. glutinis during the first $20 \mathrm{~h}$ of cultivation and produced around $41 \mathrm{~g} / \mathrm{L}$ DCW (Figure $9 \mathrm{a}$ ) with a DCW synthesis rate $4.3 \mathrm{~g} / \mathrm{l} / \mathrm{h}$ and DCW-Y reached to $48 \%$, (Figure 10a). At $32 \mathrm{~h}$, the DCW, TL, and TP of the control group were higher than the optimized group. The decrease in the biomass, lipid, and carotenoid of the optimized group was mainly related to the change in the environmental conditions, as well as adding the metal solution, which decreased the cell activity to adapt to the new culture conditions. With the experiment progression, the lipid production, as well as the total lipid productivity in the control group, were greatly enhanced compared with the optimized group, representing around a $42 \%$ and $26.4 \%$ increase, respectively. Due to the increase of lipid bodies inside the yeast cells of the control group, the DCW showed around a $21.3 \%$ increase compared to the optimized media. Interestingly, the carotenoid of the optimized group was significantly increased by around $50 \%$ compared with the control, which emphasized the role of our strategy to enhance carotenoid production. The remarkable increase in carotenoid production could be related to the use of metal supplementation such as $\mathrm{Al}^{+3}$ and $\mathrm{Ni}^{+2}$, which proved to enhance carotenoid production by reducing lipid production in the flask fermentation experiment, besides the continuous supply of phosphorous and sulfate, which restricted the lipid accumulation. In addition, the shifting of the culture conditions played a critical role in this increase. The highest production of carotenoid was $29.3 \mathrm{mg} / \mathrm{L}$ with a maximum cellular carotenoid of $426 \mu \mathrm{g}_{\text {pigment }} / \mathrm{g}_{\mathrm{DCW}}$ that was achieved at the end of cultivation with the optimized group, while the highest DCW, with the highest lipid production 
and productivity, were recorded with the control group $87.4 \mathrm{~g} / \mathrm{L}, 49.2 \mathrm{~g} / \mathrm{L}$ and $56.4 \%$, respectively, Figure 9a,b.

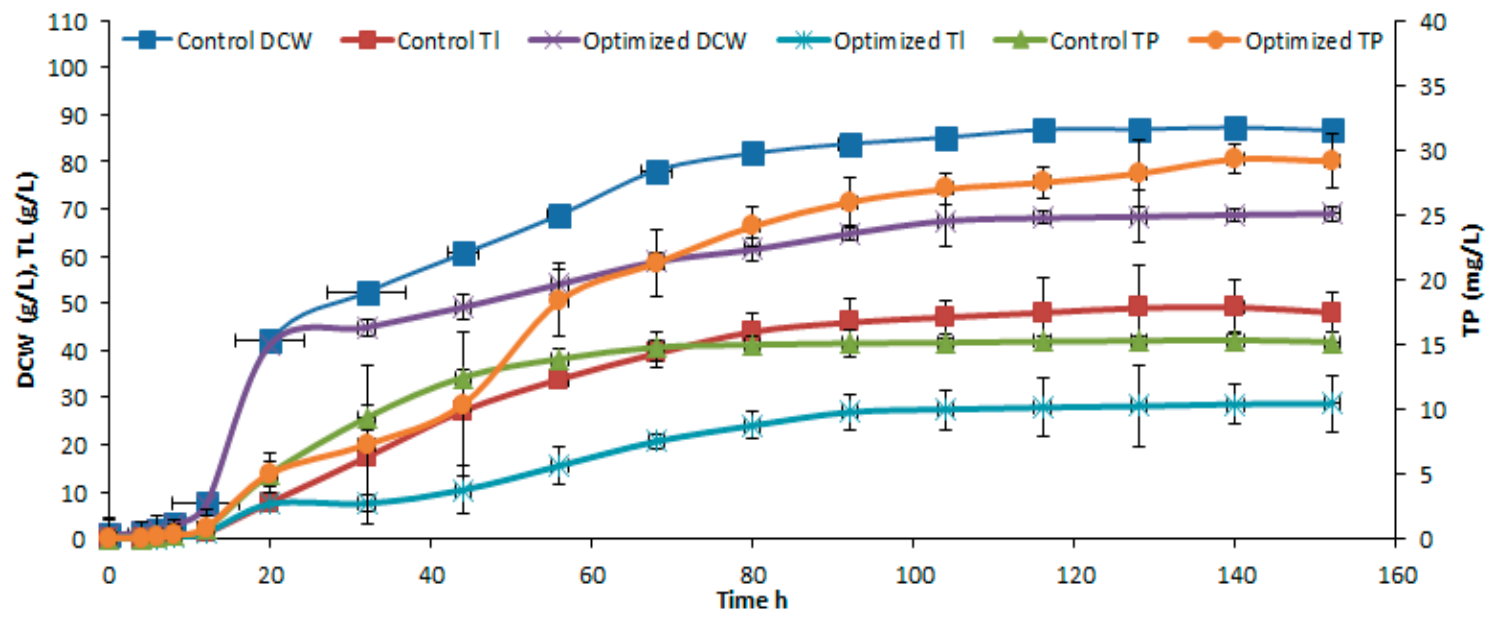

(a)

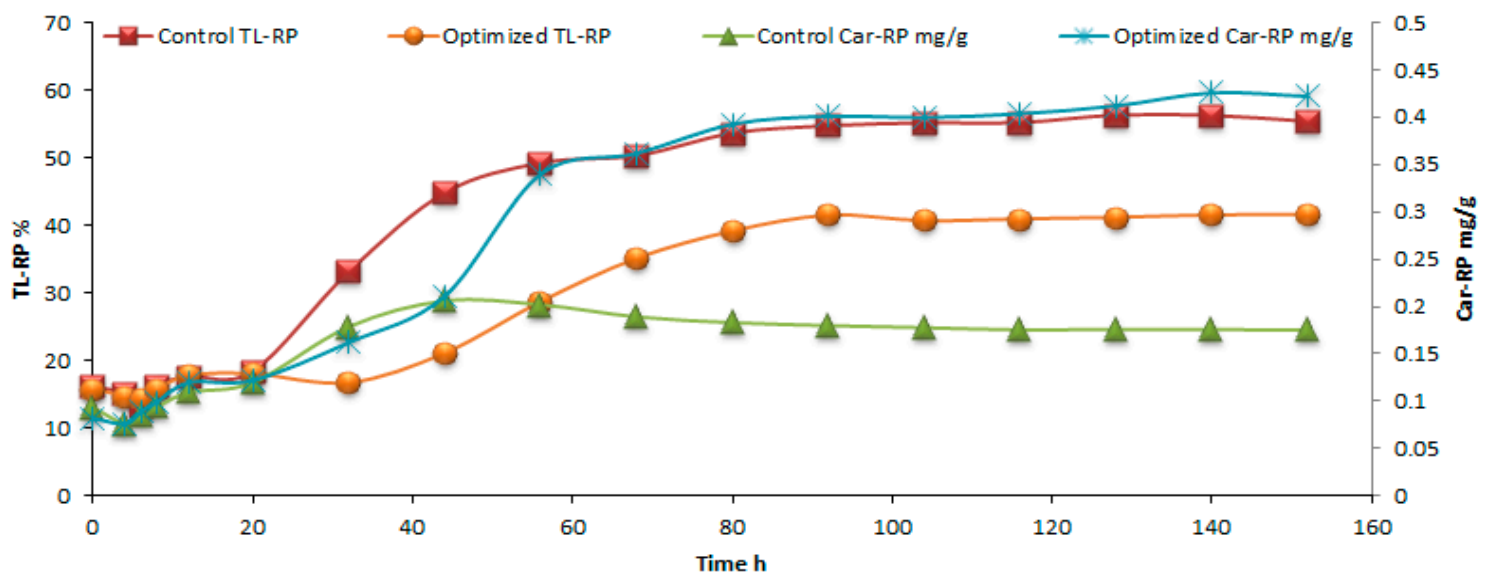

(b)

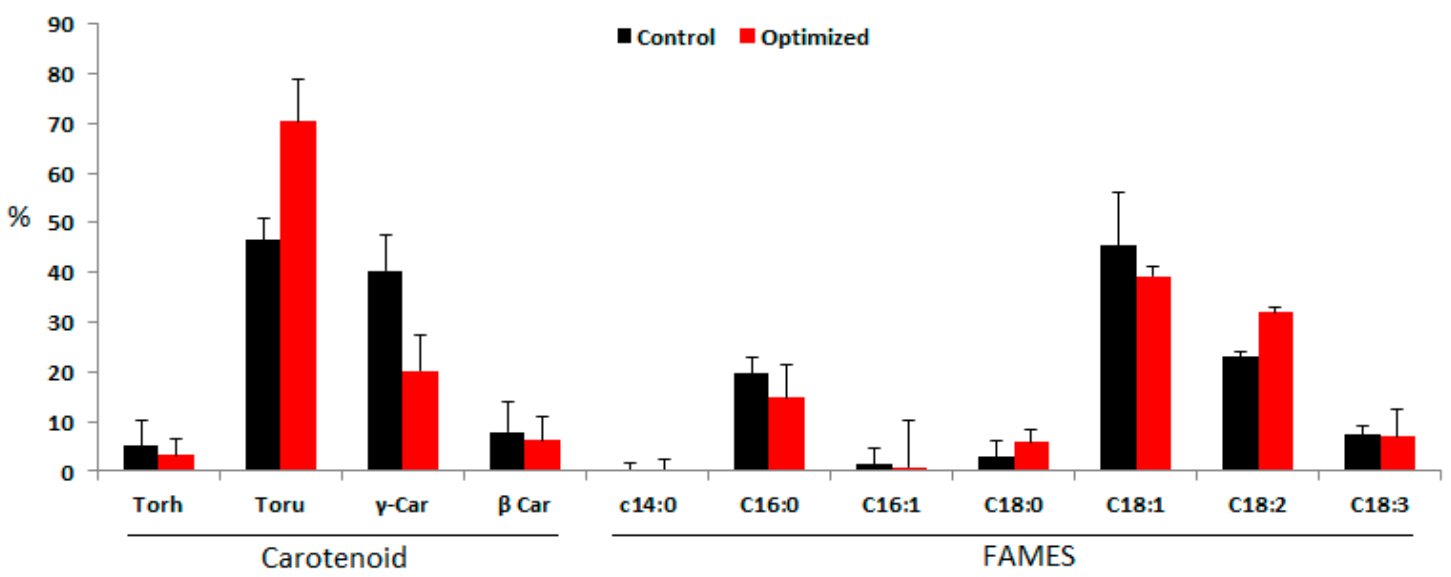

(c)

Figure 9. Cont. 


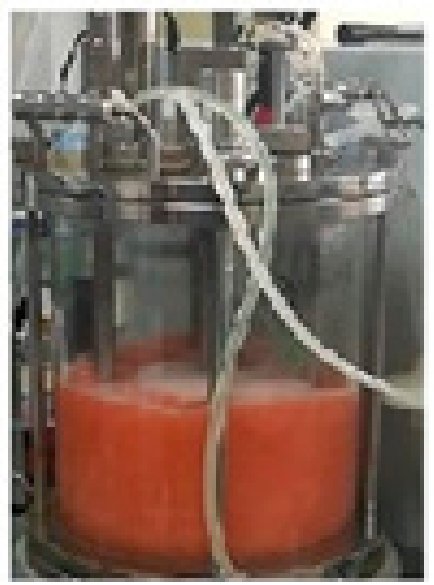

(d)

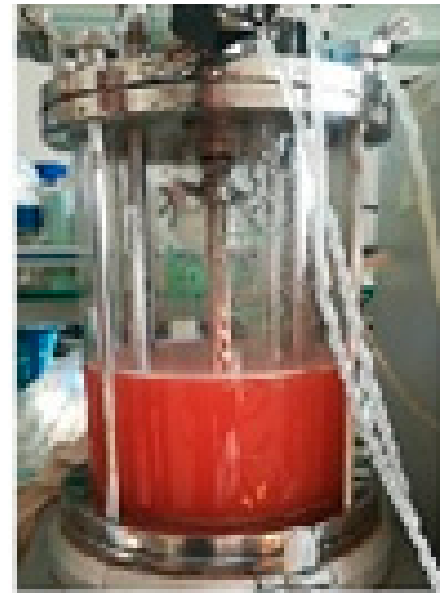

(e)

Figure 9. Effect of different fed-batch cultivation strategies on R. glutinis growth, lipid, and carotenoid production: (a) The control and optimized treatment DCW, TL and TP; (b) the control and optimized treatment TL-RP and Car-RP; (c) lipid and carotenoid profile; (d) control'biomass color at the end of cultivation; (e) Optimized' biomass color at the end of cultivation.

The kinetic analysis of the process is represented in Figure 10. The maximum of TL-Y and TL-SR were detected with the control group, $21.3(\mathrm{~g} / 100 \mathrm{~g}$ glucose) (time $=44 \mathrm{~h})$ and $0.82 \mathrm{~g} / \mathrm{L} / \mathrm{h}($ time $=44)$, respectively, which decreased with the optimized group to be $18.32 \mathrm{~g} / 100 \mathrm{~g}$ glucose (time $=68 \mathrm{~h}$ ), and $0.77 \mathrm{~g} / \mathrm{L} / \mathrm{h}($ time $=20)$, respectively, Figure 10b. The opposite was observed with the carotenoid kinetics, the maximum Car-Y and Car-SR were detected with the optimized group $0.17 \mathrm{~g} / 100 \mathrm{~g}$ glucose (time $=56 \mathrm{~h}$ ) and $0.67 \mathrm{mg} / \mathrm{L} / \mathrm{h}($ time $=56)$, respectively, Figure 10c. This result indicates the reversible relationship between lipid and carotenoid production during the same process.

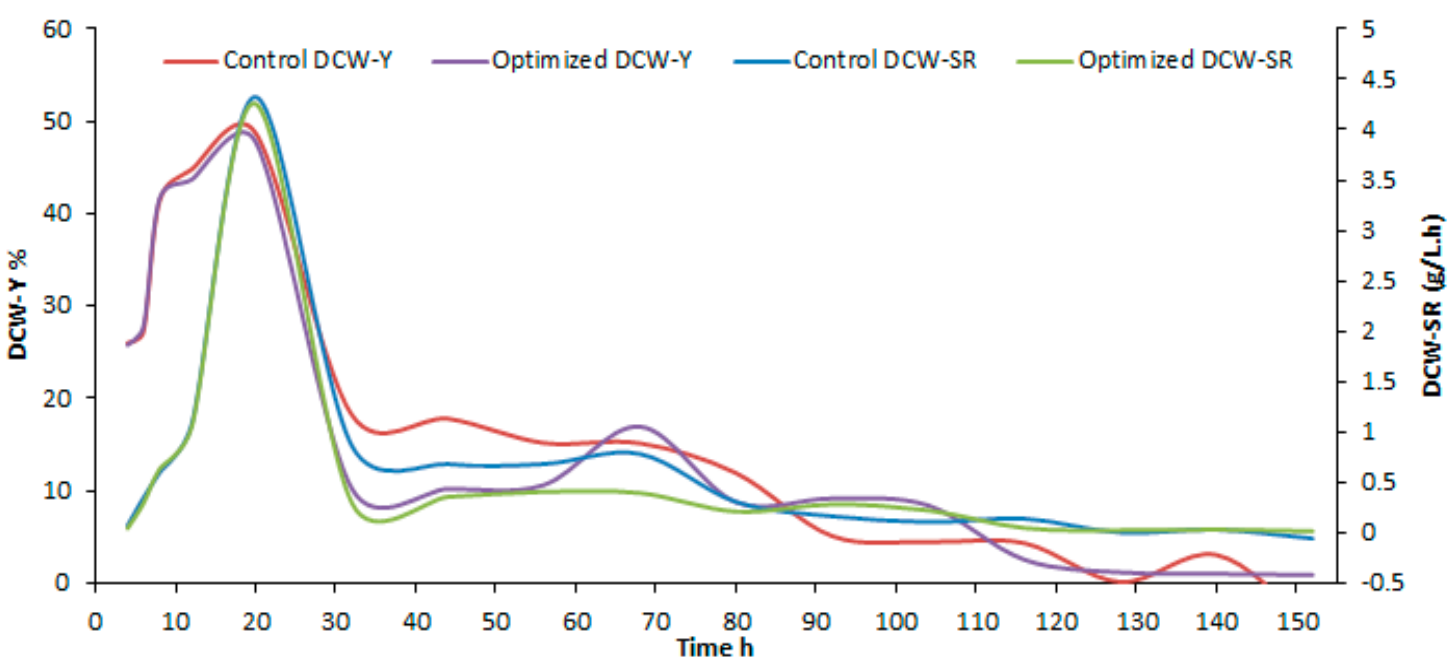

(a)

Figure 10. Cont. 


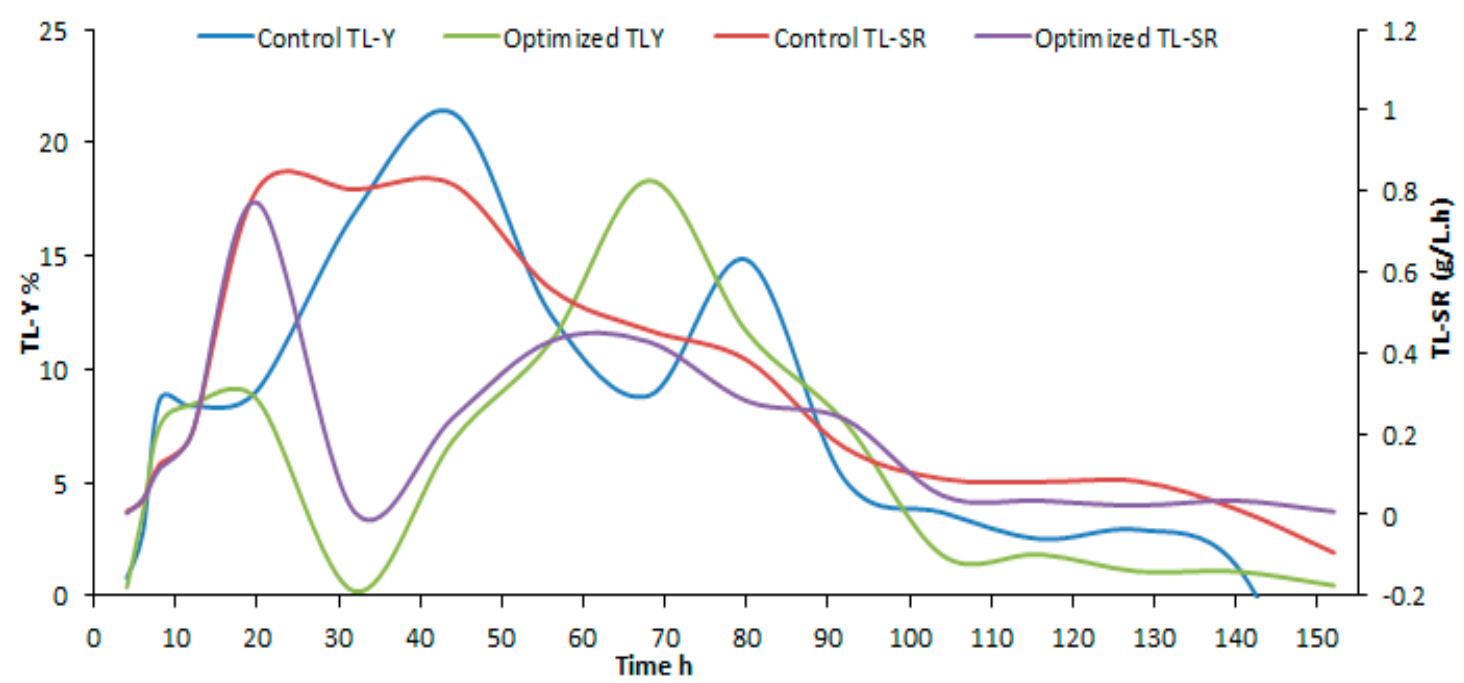

(b)

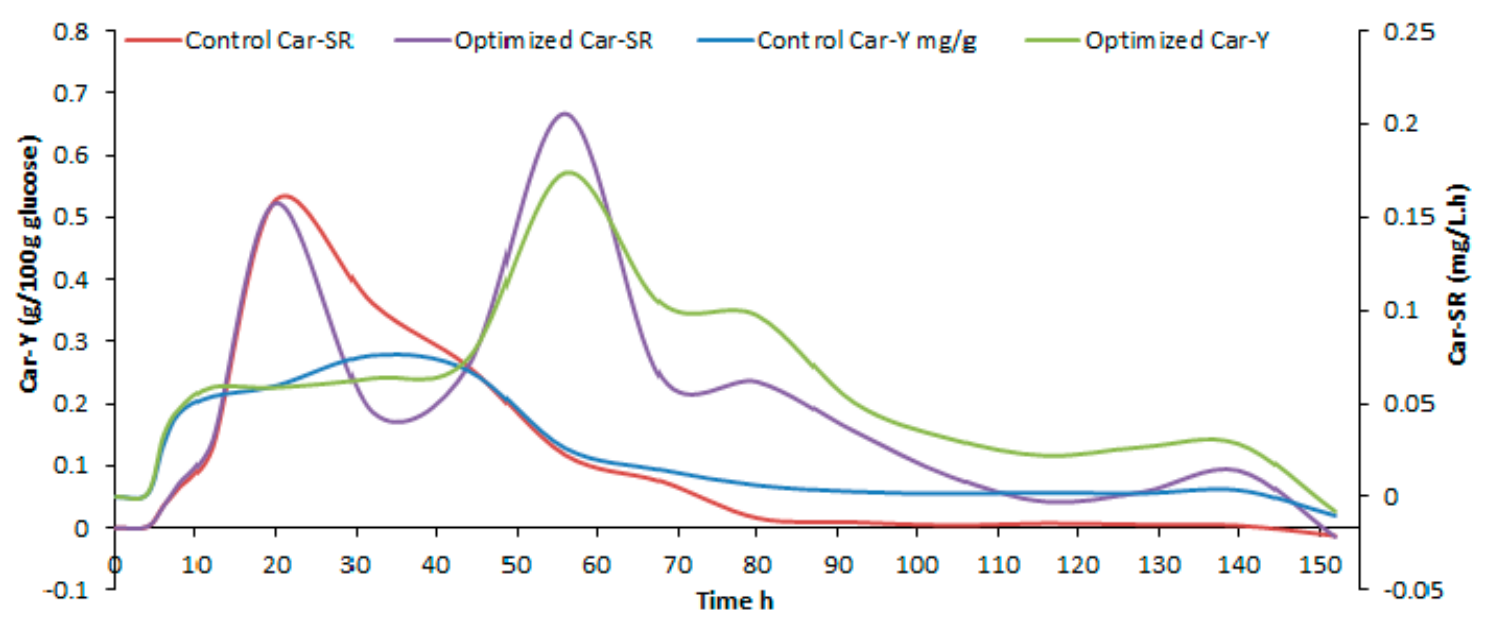

(c)

Figure 10. Kinetics parameters of different fed-batch cultivation strategies on R. glutinis growth, lipid, and carotenoid production: (a) Dry cell weight yield (DCW-Y) and dry cell weight synthesis rate (DCW-SR). (b) Total lipid yield (TL-Y) and total lipid synthesis rate (TL-SR). (c) Carotenoid yield (Car-Y) and carotenoid synthesis rate (Car-SR).

Looking at the lipid and carotenoid profile under different cultivating strategies (Figure 9c), both torulene and unsaturated fatty acids, mainly $\mathrm{C} 18: 2$, increased with the optimized group compared to the control. The torulene ratio was around $70 \%$ compared with $46 \%$ in the case of the control group. The increase in C18:2 in the optimized group may be mainly due to low incubating temperature and $\mathrm{Ba}^{+2}$ and $\mathrm{Mn}^{+2}$ supplementation, as observed in the flask fermentation experiment. In addition, increasing the torulene ratio may be related to metal supplementation, low $\mathrm{pH}$, and temperature. Honestly, the ratio of torulene in the flask fermentation was higher than the bioreactor fermentation, and this result may be related to the agitation speed beside the phosphorous concentration in the culture media, as the increase of those two parameters enhanced the $\gamma$-carotene accumulation inside the yeast cells. The differences in the biomass color under the different cultivation strategy is represented in Figure 9d,e. The intense red color in the case of the optimized group was mainly related to the increase of the torulene ratio compared with the control group.

Several fed-batch studies were done to coproduce lipid and carotenoid from red oleaginous yeasts. Dias et al. [43] used pH control fed-batch cultivation strategy for the co-production of lipids and 
carotenoids by $R$. toruloides NCYC 921, the pH change step-wise strategy, setting another Rushton impeller to the bioreactor rotor shaft led to an increase in the biomass to $127 \mathrm{~g} / \mathrm{L}$, which was higher than this study, which was mainly due to the nitrogen feeding with glucose solution during the growth phase. The carotenoid content was $0.29 \mathrm{mg} / \mathrm{g}$, which was lower than our result $\left(0.426 \mathrm{mg}_{\text {pigment }} / \mathrm{g}_{\mathrm{DCW}}\right.$ with the optimized group).

Saenge et al. [2] used R. glutinis TISTR 5159 to coproduce lipids and carotenoids grown on palm oil mill effluent. Similarly, the two-stage process was attempted as an optimal way for cell growth in the first stage and product accumulation in the second stage. The lipid yield and carotenoid production obtained in the two-stage process were higher than those in the one-stage process. Although the total carotenoid yield was higher than our result, the biomass, lipid, and polyunsaturated fatty acid were lower than the presented study.

In addition, Zhang et al. [66] used a two-stage cultivation strategy for lipid and carotenoid by the strain R. glutinis CGMCC No. 2258: The first grow step was conducted under irradiation/high temperature; the second step (product accumulation) was conducted at dark/low temperature conditions in order to induce products accumulation. The biomass, lipid content, and carotenoid reached $86.2 \mathrm{~g} / \mathrm{L}$, $26.7 \%$, and $4.2 \mathrm{mg} / \mathrm{L}$, respectively, which was lower than our results. Lipids contained $22.8 \%$ saturated fatty acid, $51.7 \%$ monounsaturated fatty acids, and $24.8 \%$ polyunsaturated fatty acid. HPLC quantified the main carotenoid to be $\beta$-carotene $68.4 \%$. Compared with our work, torulene had an intense antioxidant activity than $\beta$-carotene due to the presence of 13 double bonds [14], besides the higher ratio of polyunsaturated fatty acid, which made our colored lipid highly nutritive than Zhang et al. [66].

\section{Conclusions}

From this study, different culture conditions were investigated to correlate the production of lipid and carotenoid production by $R$. glutinis, as well as investigating the possibilities to improve the lipid and carotenoid profile of $R$. glutinis through culture conditions manipulation. The results revealed that all the studied conditions showed a reversible relationship between lipid and carotenoid production under the studied culture conditions. Studying the effect of different heavy metal stress on carotenoid and lipid production and profile was interesting. The addition of copper $0.1 \mathrm{mM}$, leading to preventing carotenoid production with increasing the saturation level of lipid profile producing around $70 \%$ palmitic and oleic acid, making it suitable for biodiesel production. While $0.1 \mathrm{mM}$ of $\mathrm{Mn}^{+2}, \mathrm{Ba}^{+2}$, and $\mathrm{Li}^{+}$led to the production of fat with the $\gamma$-carotene dominant carotenoid and unsaturated fatty acid domination, especially polyunsaturated fatty acid. $1 \mathrm{mM} \mathrm{NiSO}_{4}$ enhanced both the cellular carotenoid as well as torulene domination by $R$. glutinis, which accompanied $81 \%$ unsaturated fatty domination, where oleic acid represented $61 \%$ of the total lipid. Finally, the metallo-sulfo-phospho-glucose feeding approach combined with the $\mathrm{pH}$-temperature shifting strategy, proved to be an effective approach for the production of carotenoid $(29.3 \mathrm{mg} / \mathrm{L})$, specifically torulene $(71 \%)$ from $R$. glutinis. This study provides a significant understanding of the relationship between lipid and carotenoid production by R. glutinis under various culture conditions. This has led to a potential fed-batch strategy to enhance carotenoid, especially torulene production, by $R$. glutinis to be competitive among other relative studies and could be useful for the industrial production of healthy nutritive pigment.

Supplementary Materials: The following are available online at http://www.mdpi.com/2227-9717/8/2/140/s1, Supplementary material 1: Figure S1. Different corrected total cell fluorescence (CTCF) value calculated by using image j software; (a) CTCF values of different carbon sources' Nile-red stained cells, (b) CTCF values of different $\mathrm{pH}$ degrees' Nile-red stained cells, (c) CTCF values of different temperature' Nile-red stained cells, (d) CTCF values of different agitation' Nile-red stained cells, (e) CTCF values of different phosphorous concentration' Nile-red stained cells, (f) CTCF values of different metal treated Nile-red stained cells. Table S1. Significance of different carbon sources on $R$. glutinis growth, lipid, and carotenoid production after 3 and 6 days. Table S2. Multivariate test to detect the significance of different carbon sources on $R$. glutinis growth, lipid, and carotenoid production after 3 and 6 days. Table S3. Significance of different pH degree on R. glutinis growth, lipid, and carotenoid production. Table S4. Multivariate test to detect the significance of different $\mathrm{pH}$ degrees on $R$. glutinis growth, lipid, and carotenoid production after 3 and 6 days. Table S5. Significance of different incubation temperatures on R. glutinis growth, lipid, and carotenoid production. Table S6. Multivariate test to detect the significance 
of different Temperature degrees on R. glutinis growth, lipid, and carotenoid production after 3 and 6 days. Table S7. Significance of different agitation speed on DCW, lipid and carotenoid production by R. glutinis. Table S8. Multivariate test to detect the significance of different agitation speed on R. glutinis growth, lipid, and carotenoid production after 3 and 6 days. Table S9. Significance of different phosphorus concentrations (initial C/P molar ratio) on $R$. glutinis growth, lipid and carotenoid production after 3 and 6-day incubation at $28^{\circ} \mathrm{C}$ and $180 \mathrm{rpm}$. Table S10. Multivariate test to detect the significance of different carbon to phosphorous ratio (C/P) on R. glutinis growth, lipid, and carotenoid production after 3 and 6 days. Supplementary Material 2; Excel sheet 1. correlation coefficient statistic. Excel sheet 2. Statistical analysis of the detection of individual carotenoid by HPLC. Excel sheet 3. Statistical analysis of the detection of fatty acid methyl esters by GC.

Author Contributions: Conceptualization, Y.B.; experimentation and writing-original draft preparation, N.E.; data analysis and investigation, N.E., M.E.; review and editing, Y.B., N.E. All authors have read and agree to the published version of the manuscript.

Funding: This research received no external funding.

Conflicts of Interest: The authors declare no conflict of interest.

\section{References}

1. Kot, A.; Błażejak, S.; Kurcz, A.; Gientka, I.; Kieliszek, M. Rhodotorula glutinis-Potential source of lipids, carotenoids, and enzymes for use in industries. Appl. Microbiol. Biotechnol. 2016, 100, 6103-6117. [CrossRef] [PubMed]

2. Saenge, C.; Cheirslip, B.; Suksaroge, T.T.; Bourtoom, T. Potential use of oleaginous red yeast Rhodotorula glutinis for the bioconversion of crude glycerol from biodiesel plant to lipids and carotenoids. Process Biochem. 2011, 46, 210-218. [CrossRef]

3. Miles, E.A.; Calder, P.C. Modulation of immune function by dietary fatty acids. Proc. Nutr. Soc. 1998, 57, 277-292. [CrossRef] [PubMed]

4. Sales-Campos, H.; Reis de Souza, P.; Peghini, C.B.; Da Silva, J.S.; Cardoso, C.R. An Overview of the Modulatory Effects of Oleic Acid in Health and Disease. Mini. Rev. Med. Chem. 2013, 13, 201-210. [CrossRef]

5. Owen, R.W.; Mier, W.; Giacosa, A.; Hull, W.E.; Spiegelhalder, B.; Bartsch, H. Phenolic compounds and squalene in olive oils: The concentration and antioxidant potential of total phenols, simple phenols, secoiridoids, lignans and squalene. Food Chem. Toxicol. 2000, 38, 647-659. [CrossRef]

6. Panagiotakos, D.B.; Dimakopoulou, K.; Katsouyanni, K.; Bellander, T.; Grau, W.K.; Lanki, T.; Pistelli, R.; Schneider, A.; Peters, A. Mediterranean diet and inflammatory response in myocardial infarction survivors. Int. J. Epidemiol. 2009, 38, 856-866. [CrossRef]

7. Tere's, S.; Barcelo'-Coblijn, G.; Benet, M.; A'lvarez, R.; Bressani, R.; Halver, J.E.; Escriba, P.V. Oleic acid content is responsible for the reduction in blood pressure induced by olive oil. Proc. Natl. Acad. Sci. USA 2008, 37, 13811-13816. [CrossRef]

8. Besler, H.T.; Grimble, R.F. Comparison of the modulatory influence of maize and olive oils and butter on metabolic responses to endotoxin in rats. Clin. Sci. 1995, 66, 59-66. [CrossRef]

9. Ferrara, L.A.; Raimondi, A.S.; Episcopo, L.; Guida, L.; Dello Russo, A.; Marotta, T. Olive oil and reduced need for antihypertensive medications. Arch. Intern. Med. 2000, 160, 837-842. [CrossRef]

10. Kremer, M.; Lawrence, D.A.; Jubiz, W.; Digiacomo, R.; Rynes, R.; Bartholomew, L.E.; Sherman, M. Dietary Fish Oil And Olive Oil Supplementation In Patients With Rheumatoid Arthritis. Arthritis Rheumatol. 1990, 33, 810-820. [CrossRef]

11. Martin-Moreno, J.M.; Willett, W.C.; Gorgojo, L.; Banegas, J.R.; Rodriguez-Artalejo, F.; Fernandez-Rodriguez, J.C.; Maisonneuve, P.; Boyle, P. Dietary fat, olive oil intake and breast cancer risk. Int. J. Cancer 1994, 58, 774-780. [CrossRef] [PubMed]

12. Lipworth, L.; Martinez, M.E.; Angell, J.; Hsieh, C.C.; Trichopoulos, D. Olive Oil and Human Cancer: An Assessment of the Evidence. Prev. Med. 1997, 26, 181-190. [CrossRef] [PubMed]

13. Kot, A.M.; Błazejak, S.; Kieliszek, M.; Gientka, I.; Bry's, J. Simultaneous Production of Lipids and Carotenoids by the Red Yeast Rhodotorula from Waste Glycerol Fraction and Potato Wastewater. Appl. Biochem. Biotechnol. 2019, 1-19. [CrossRef] [PubMed]

14. Ageitos, J.M.; Vallejo, J.A.; Veiga-crespo, P.; Villa, T.G. Oily yeasts as oleaginous cell factories. Appl Microbiol. Biotechnol. 2011, 90, 1219-1227. [CrossRef] 
15. Kot, A.M.; Błazejak, S.; Gientka, I.; Kieliszek, M.; Bry's, J. Torulene and torularhodin: "New" fungal carotenoids for industry? Microbl. Cell Fact. 2018, 100, 6103-6117. [CrossRef]

16. Krinsky, N.I.; Johnson, E.J. Carotenoid actions and their relation to health and disease. Mol. Asp. Med. 2005, 26, 459-516. [CrossRef]

17. Brown, L.; Rimm, E.B.; Seddon, J.M.; Giovannucci, E.L.; Chasan-Taber, L.; Spiegelman, D.; Willett, W.C.; Hankinson, S.E. A prospective study of carotenoid intake and risk of cataract extraction in US men. Am. J. Clin. Nutr. 1999, 70, 517-524. [CrossRef]

18. Beatty, S.; Nolan, J.; Kavanagh, H.; Donovan, O.O. Macular pigment optical density and its relationship with serum and dietary levels of lutein and zeaxanthin. ABB 2004, 430, 70-76. [CrossRef]

19. Stahl, W.; Sies, A.H. Carotenoids and Flavonoids Contribute to Nutritional Protection against Skin Damage from Sunlight. Mol. Biotechnol. 2007, 37, 26-30. [CrossRef]

20. Fraser, P.D.; Bramley, P.M. The biosynthesis and nutritional uses of carotenoids. Prog. Lipid Res. 2004, 43, 228-265. [CrossRef]

21. Mata-gómez, L.C.; Montañez, J.C.; Méndez-zavala, A.; Aguilar, C.N. Biotechnological production of carotenoids by yeasts: An overview. Microbl. Cell Fact. 2014, 13, 1-11. Available online: http://www. microbialcellfactories.com/content/13/1/12 (accessed on 1 January 2014). [CrossRef] [PubMed]

22. Braunwald, T.; Schwemmlein, L.; Graeff-Hönninger, S.; French, W.T.; Hernandez, R.; Holmes, W.E.; Claupein, W. Effect of different $\mathrm{C} / \mathrm{N}$ ratios on carotenoid and lipid production by Rhodotorula glutinis. Appl. Microbiol. Biotechnol. 2013, 97, 6581-6588. [CrossRef]

23. Tkáčová, J.; Čaplová, J.; Klempová, T.; Čertík, M. Correlation between lipid and carotenoid synthesis in torularhodin-producing Rhodotorula Glutinis. Ann. Microbiol. 2017, 67, 541-551. [CrossRef]

24. Elfeky, N.; Elmahmoudy, M.; Zhang, Y.; Guo, J.; Yongming, B. Lipid and Carotenoid Production by Rhodotorula glutinis with a Combined Cultivation Mode of Nitrogen, Sulfur and Aluminium Stress. Appl. Sci. 2019, 9, 2444. [CrossRef]

25. Schulze, K.L. The Effect of Phosphate Supply on the Rate of Growth and Fat Formation in Yeasts. Appl. Microbiol. 1956, 4, 207-210. [CrossRef]

26. Baldrian, P.; Gabriel, I. Influence of Cadmium and Mercury on Activities of Ligninolytic Enzymes and Degradation of Polycyclic Aromatic Hydrocarbons by Pleurotus ostreatus in Soil. Appl. Environ. Microbiol. 2000, 66, 2471-2478. [CrossRef]

27. Yang, J.; Cao, J.; Xing, G.; Yuan, H. Lipid production combined with biosorption and bioaccumulation of cadmium, copper, manganese and zinc by oleaginous microalgae Chlorella minutissima UTEX2341. Bioresour. Technol. 2015, 175, 537-544. [CrossRef]

28. Goswami, L.; Manikandan, N.A.; Pakshirajan, K.; Pugazhenthi, G. Simultaneous heavy metal removal and anthracene biodegradation by the oleaginous bacteria Rhodococcus opacus. 3 Biotech 2017, 7, 1-9. [CrossRef]

29. El-Banna, A.A.; Abd El-Razek, A.M.; El-Mahdy, A.R. Some Factors Affecting the Production of Carotenoids by Rhodotorula glutinis var. glutinis. Food Nutr. Sci. 2012, 3, 64-71. [CrossRef]

30. Bhosale, P.B.; Gadre, V. Production of $\beta$-carotene by a mutant of Rhodotorula glutinis. Appl. Microbiol. Biotechnol. 2001, 55, 423-427. [CrossRef]

31. Sitepu, R.; Sestric, R.; Ignatia, L.; Levin, D.; German, J.; Gillies, L.A.; Almada, L.A.; Boundy-Mills, K.L. Manipulation of culture conditions alters lipid content and fatty acid profiles of a wide variety of known and new oleaginous yeast species. Bioresour. Technol. 2013, 144, 360-369. [CrossRef] [PubMed]

32. Miller, G.L. Use of Dinitrosalicylic Acid Reagent for Determination of Reducing Sugar. Anal. Chem. 1959, 31, 426-428. [CrossRef]

33. Miloski, K.; Wallace, K.; Fenger, A.; Schneider, E.; Bendinskas, K. Comparison of Biochemical and Chemical Digestion and Detection Methods for Carbohydrates. Am. J. Undergrad. Res. 2019, 7,7-18. [CrossRef]

34. Kimura, K.; Yamaoka, M.; Kamisaka, Y. Rapid estimation of lipids in oleaginous fungi and yeasts using Nile red fluorescence. J. Microbiol. Methods 2004, 56, 331-338. [CrossRef]

35. Available online: https://theolb.readthedocs.io/en/latest/imaging/measuring-cell-fluorescence-using-imagej. html (accessed on 1 January 2014).

36. Mishra, S.K.; Suh, W.I.; Farooq, W.; Moon, M.; Shrivastav, A.; Park, M.S.; Yang, J.W. Rapid quantification of microalgal lipids in aqueous medium by a simple colorimetric method. Bioresour. Technol. 2014, 155, 330-333. [CrossRef] [PubMed] 
37. Van Wychen, S.; Ramirez, K.; Laurens, L.M. Determination of Total Lipids as Fatty Acid Methyl Esters (FAME) by in situ Transesterification. NREL 2013, 303, 275-3000.

38. Frengova, G.; Sirnova, E.; Pavlova, K.; Beshkova, D. Formation of Carotenoids by Rhodotorula glutinis in whey ultrafiltrate. Biotechnol. Bioeng. 1994, 44, 888-894. [CrossRef]

39. Weber, R.W.; Anke, H.; Davoli, P. Simple method for the extraction and reversed-phase high-performance liquid chromatographic analysis of carotenoid pigments from red yeasts (Basidiomycota, Fungi). J. Chromatogr. A 2007, 1145, 118-122. [CrossRef]

40. Certik, M.; Shimizu, S. Kinetic analysis of oil biosynthesis by an arachidonic acid-producing fungus, Mortierella alpina 1S-4. Appl. Microbiol. Biotechnol. 2000, 54, 224-230. [CrossRef]

41. Patel, A.; Pruthi, V.; Singh, R.P.; Pruthi, P.A. Synergistic effect of fermentable and non-fermentable carbon sources enhances accumulation in oleaginous yeast Rhodosporidium kratochvilovae HIMPA1. Bioresour. Technol. 2015, 188, 136-144. [CrossRef]

42. Karamerou, E. Bioprocessing Strategies for the Cultivation of Oleaginous Yeasts on Glycerol. PhD Thesis, School of Chemical Engineering and Analytical Science, University of Manchester, UK, 2016.

43. Dias, C.; Sousa, S.; Caldeira, J.; Reis, A. New dual-stage pH control fed-batch cultivation strategy for the improvement of lipids and carotenoids production by the red yeast Rhodosporidium toruloides NCYC 921. Bioresour. Technol. 2015, 189, 309-318. [CrossRef] [PubMed]

44. Johnson, V.; Singh, M.; Saini, V.S.; Sista, V.R.; Yadav, N.K. Effect of pH on lipid accumulation by an oleaginous yeast: Rhodotorula glutinis IIP-30. World J. Microbiol. Biotechnol. 1992, 8, 382-384. [CrossRef]

45. Milkessa, T.; Marizeth, J.; Carolina, G.; Laurinda, P.; Pohl, C. Optimization of cultivation conditions for biotechnological production of lipid by Rhodotorula kratochvilovae (syn, Rhodosporidium kratochvilovae) SY89 for biodiesel preparation. 3 Biotech 2017, 7, 1-11.

46. Dhaliwal, M.K.; Chandra, N. Optimization of carotenoids production by Rhodotorula mucilaginosa. IJPSR 2015, 3, 1161-1165.

47. Zhao, Y.; Guo, L.; Xia, Y.; Zhuang, X.; Chu, W. Isolation, Identification of Carotenoid-Producing Rhodotorula sp. from Marine Environment and Optimization for Carotenoid Production. Mar. Drugs 2019, 17, 161. [CrossRef] [PubMed]

48. Hadi, S. Effect of Temperature and $\mathrm{pH}$ on the Growth Kinetics and Carotenoid Production by Sporobolomyces ruberrimus H110 Using Technical Glycerol as Carbon Source. Iran. J. Chem. Chem. Eng. 2006, 25, 59-64.

49. Saad, N.; Abdeshahian, P.; Kalil, M.S.; Wan Yusoff, W.M.; Abdul Hamid, A. Optimization of Aeration and Agitation Rate for Lipid and Gamma Linolenic Acid Production by Cunninghamella bainieri 2A1 in Submerged Fermentation Using Response Surface Methodology. Sci. World J. 2014, 1-12. [CrossRef]

50. Zhou, Y.; Han, L.; He, H.; Yu, D.; Feng, J.; Zhang, X. Effects of agitation, aeration and temperature on production of a novel glycoprotein gp-1 by streptomyces kanasenisi zx01 and scale-up based on volumetric oxygen transfer coefficient. Molecules 2018, 23, 125. [CrossRef]

51. Vlaev, S.; Pavlova, K.; Rusinova-Videva, S.; Georgieva, K.; Georgiev, D. Agitation effects and kinetic constants of exoglucomannan production by Antarctic yeast strain in a stirred tank bioreactor. Chem. Biochem. Eng. 2016, 30, 393-400. [CrossRef]

52. Dai, C.; Tao, J.; Xie, F.; Dai, Y.J.; Zhao, M. Biodiesel generation from oleaginous yeast Rhodotorula glutinis with xylose assimilating capacity. Afr. J. Biotechnol. 2007, 6, 2130-2134.

53. El-Fadaly, A.H.; El-Naggar, N.; El-Sayed, M. Single Cell Oil Production by an Oleaginous Yeast Strain in a Low cost cultivation medium. Res. J. Microbiol. 2009, 4, 301-313. [CrossRef]

54. Wang, Y.; Zhang, S.; Zhu, Z.; Shen, H.; Lin, X.; Jin, X.; Jiao, X.; Zhao, Z. Biotechnology for Biofuels Systems analysis of phosphate-limitation-induced lipid accumulation by the oleaginous yeast Rhodosporidium toruloides. Biotechnol. Biofuels 2018, 1-15. [CrossRef]

55. Buzzini, P.; Martini, A.; Gaetani, M.; Turchetti, B.; Pagnonib, U.; Davoli, P. Optimization of carotenoid production by Rhodotorula graminis DBVPG 7021 as a function of trace element concentration by means of response surface analysis. Enzym. Microb. Technol. 2005, 36, 687-692. [CrossRef]

56. Bhosale, P. Environmental and cultural stimulants in the production of carotenoids from microorganisms. Appl. Microbiol. Biotechnol. 2004, 63, 351-361. [CrossRef] [PubMed]

57. Latha, B.V.; Jeevaratnam, K.; Murali, H.S.; Manja, K.S. Influence of growth factors on carotenoid pigmentation of Rhodotorula glutinis DFR-PDY from natural source. Indian J. Biotechnol. 2004, 4, 353-357. 
58. Frengova, G.I.; Beshkova, D.M. Carotenoids from Rhodotorula and Phaffia: Yeasts of biotechnological importance. J. Ind. Microbiol. Biotechnol. 2009, 36, 163-180. [CrossRef]

59. Wongsnansilp, T.; Juntawong, N.; Wu, Z. Effects of phosphorus on the growth and chlorophyll fluorescence of a Dunaliella salina strain isolated from saline soil under nitrate limitation. J. Biol. Res. 2016, 89, 51-55. [CrossRef]

60. Forján, E.; Garbayo, I.; Bejarano, C.; Vílchez, C. Enhancement of carotenoid production in Nannochloropsis by phosphate and sulphur limitation. In Communicating Current Research and Educational Topics and Trends in Applied Microbiology; Microbiology Book Series; Formatex: Badajoz, Spain, 2007; Volume 1, pp. 356-364. ISBN 978-84-611-9421-6.

61. Kot, A.M.; Błazejak, S.; Kurcz, A.; Bry's, J.; Gientka, I.; Bzducha-Wróbel, A.; Maliszewska, M.; Reczek, L. Effect of initial $\mathrm{pH}$ of medium with potato wastewater and glycerol on protein, lipid and carotenoid biosynthesis by Rhodotorula glutinis. Electron. J. Biotechnol. 2017, 27, 25-31. [CrossRef]

62. Suutari, M.; Rintamliki, A.; Laakso, S. The Effect of Temperature on Lipid Classes and Their Fatty Acid Profiles in Lipomyces starkeyi. JAOCS 1996, 73, 1071-1073. [CrossRef]

63. Miranti, A.; Arbianti, R.; Utami, T. Effect of $\mathrm{pH}$, temperature and medium agitation rate in production of AA, DHA, EPA from Aspergillus oryzae with submerged fermentation. IOP Conf. Ser. Earth Environ. Sci. 2018, 105, 012113. [CrossRef]

64. Hu, H.; Wang, H.; Li, J.; Ma, L.; Shen, X.; Zeng, R. Evaluation of the effect of agitation speed on the growth and high-value LC-PUFA formation of Porphyridium cruentum based on basic rheological analysis. J. Chem. Technol. Biotechnol. 2019, 7, 2158-2166. [CrossRef]

65. Davoli, P.; Mierau, V.; Weber, R.W.S. Carotenoids and fatty acids in red yeasts Sporobolomyces roseus and Rhodotorula glutinis. Appl. Biochem. Microbiol. 2004, 40, 392-397. [CrossRef]

66. Zhang, Z.; Zhang, X.; Tan, T. Lipid and carotenoid production by Rhodotorula glutinis under irradiation/high-temperature and dark/low-temperature cultivation. Bioresour. Technol. 2014, 157, 149-153. [CrossRef] [PubMed]

(C) 2020 by the authors. Licensee MDPI, Basel, Switzerland. This article is an open access article distributed under the terms and conditions of the Creative Commons Attribution (CC BY) license (http://creativecommons.org/licenses/by/4.0/). 